REVISTA DE DERECHO UNED, NÚM. 18, 2016

\title{
CONSIDERACIONES CRÍTICAS EN TORNO A LA EXISTENCIA DE INTERPOLACIONES EN LA RESCISIÓN POR LAESIO ULTRADIMIDIUM
}

\author{
CRITIQUE REGARDING POSSIBLE INTERPOLATIONS IN THE \\ CONCEPT OF RESCISSION DUE TO LAESIO ULTRADIMIDIUM
}

\author{
Silvia Valmaña VaLmaña
}

Tortosa, 21 de diciembre de 2015

Resumen: El origen de la rescisión por laesio ultradimidium que aparece en los dos rescriptos del Código de Justiniano, CI.4,44,2 y CI.4,44,8, ha sido objeto de críticas por parte de la doctrina romanista, en relación con la interpolación de los mismos.

Un sector de la misma defiende la tesis de que la rescisión por lesión sería una introducción de los compiladores de Justiniano, dado que las incorrecciones gramaticales, la falta de coordinación sintáctica y su difícil armonización con otros textos del Corpus Iuris Civilis y del Codex Theodosianus, unido a la teoría del iustum pretium, demostrarían la interpolación de ambos rescriptos.

Otro sector de la doctrina mantiene la teoría de que esta institución debe su origen al emperador Diocleciano, descartando cualquier tipo de interpolación en los rescriptos aludidos.

$\mathrm{Y}$ existe la postura intermedia de los autores que opinan que, a pesar de que la rescisión por lesión ultra dimidium debe su origen a Diocleciano, admiten la posibilidad de que ambos rescriptos fueron revisados por los compiladores justinianeos, por lo que no tendrían en su origen el mismo alcance que en el Derecho de Justiniano.

Abstract: The origin of the concept of rescission due to laesio ultradimidium, which appears in the Codex Justinianus rescripts 
CJ.4,44,2 and CJ.4,44,8, has been debated in the field of Roman Law regarding its possible interpolation in these rescripts.

One line of thought claims that the rescission due to lesion concept was introduced into the rescripts by the compilers of the Codex Justinianus - grammatical errors, a lack of syntactic coordination, and a difficult harmonization with other texts from the Corpus Iuris Civilis and the Codex Theodosianus, taken together with the iustum pretium theory would demonstrate that it was interpolated into both rescripts by the compilers.

A different line of thought holds to the theory that this institution owes its origin to emperor Diocletian, ruling out any kind of interpolation in the rescripts.

As authors of this work, we maintain a mid-way position between these two. Although we believe the idea of rescission due to laesio ultradimidium has its origin with Diocletian, we accept the possibility that both rescripts could have been revised by the Justinian compilers and, thus, would not have the same legal meaning as they would have originally had in Justinian Law.

Palabras clave: Interpolación, compraventa, rescisión por laesio ultradimidium, justo precio, humanum est.

Keywords: Interpolation, buying and selling, rescission due to ultradimidium lesion, just price, humanum est.

Recepción original: 21/12/2015

Aceptación original: 06/04/2016

Sumario: I. Introducción: La polémica sobre la existencia de interpolaciones en materia de rescisión por laesio ultradimidium. II. Problemática exegética de los rescriptos CI.4,44,2 y CI.4,44,8 y la teoría interpolacionista. III. La teoría de la autenticidad: Diocleciano y el origen de los rescriptos. IV. Teorias intermedias sobre el origen y la interpolación de los rescriptos: los compiladores justinianeos. V. Conclusiones. VI. Bibliografía.

\section{INTRODUCCIÓN: LA POLÉMICA SOBRE LA EXISTENCIA DE INTERPOLACIONES EN MATERIA DE RESCISIÓN POR LAESIO ULTRADIMIDIUM}

Durante los dos últimos siglos la institución de la rescisión por laesio ultradimidium ha sido objeto de diversas críticas por parte de autores romanistas, en relación con la interpolación de los dos res- 
criptos del Código de Justiniano CI.4,44,2 y CI.4,44,8, que dieron origen a la misma.

Sobre la teoría de las interpolaciones Kaser es de la opinión que a pesar de que los textos clásicos del Corpus Iuris Civilis de Justiniano fueron objeto de modificaciones y alteraciones, han conservado su originalidad $^{1}$. Los compiladores que fueron expresamente autorizados por Justiniano, guardarían respeto por la tradición clásica en la medida que fuera posible, pero las discordancias de los textos antiguos o su imposibilidad de aplicación a las nuevas necesidades, haría posible su modificación, alterando los textos genuinos, que se traducirían en adiciones, omisiones, cambios o sustracciones de su contenido, para acomodarlos a las necesidades de la época y a su finalidad codificadora ${ }^{2}$.

Se barajan varias hipótesis de que el responsable de estas interpolaciones fuera Triboniano ${ }^{3}$, a partir de que el emperador Justinia-

${ }^{1}$ Vid. KASER, M., Las interpolaciones en las fuentes jurídicas romanas, Granada 1998, 67-81. este autor distingue las interpolaciones justinianeas en tres grupos, las que contienen alteraciones sustanciales que son adaptaciones a las leyes reformadoras y las innovaciones introducidas a través de las interpolaciones; los cambios relacionados con el proceso de base funcionarial, y los arreglos y adaptaciones por cambio de lugar del texto.

${ }^{2}$ KUNKEL, W., Historia del Derecho Romano, Barcelona 1970, cit., 179-181. Este mismo autor al hablar de las alteraciones que sufrieron los escritos de los juristas clásicas a través de la intervención de la comisión compiladora de Justiniano, dice que dichos textos ya sufrieron considerables alteraciones mucho antes de Justiniano, en la época alto-postclásica; GONZÁLEZ FERNÁNDEZ, R., Las estructuras ideológicas del Código de Justiniano, cit., 46, este autor opina que «los textos utilizados por los comisarios justinianeos habrían sufrido alteraciones antes de la época justinianea y que habrían sido alterados por glosas interlineadas o marginales añadidas en época postclásica»; también KASER, M., Las interpolaciones en las fuentes jurídicas romanas, cit., 67-68; en cambio PALAZZINI FINETTI, L., Storia della recerca delle interpolazioni nel Corpus iuris giustinianeo, Milano 1953, 115-116, considera que las Emblemata Triboniani corromperían la pureza de la tradición jurídica romana, lo que dificultaría el estudio histórico del Corpus Iuris y, por lo tanto, el trabajo de reconstrucción del derecho romano clásico, como principal objetivo de cualquier verdadero seguidor de la escuela Culta.

3 ORTOLAN, M. «Historia de la Legislación Romana», Madrid 1869, 393-394; vid. ORTOLAN, M. "Historia de la Legislación Romana», cit., 400, según este mismo autor Triboniano fue un jurisconsulto que se dedicó al estudio de las antiguas obras de jurisprudencia, y dirigió la redacción de todo el cuerpo del derecho, y a él se le atribuye el mérito y los defectos del Corpus Iuris Civilis de Justiniano; TROPLONG, De l'influence du Christianisme sur le droit civil des romains, Bruxelles 1844, 49; GÓMEZ DE LA SERNA, P., Curso Histórico-Exegético del Derecho Romano comparado con el Español, I, Madrid 1869, 101; ARANGIO RUIZ, V., Historia del Derecho Romano, Madrid 1974, 467-468; GÓMEZ DE LA SERNA, P., Curso Histórico-Exegético del Derecho Romano comparado con el Español, cit. 91, hace una breve referencia a las llamadas emblemata Triboniani que consistían en las modificaciones y adiciones realizadas en los fragmentos de los antiguos jurisconsultos; sobre las 
no le confiase hacer una colección general que comprendiera las constituciones de sus antecesores y las respuestas de los jurisconsultos, formando un cuerpo del derecho civil, dando lugar a lo que sería el Código de Justiniano ${ }^{4}$. En su composición se cometerían algunos errores tales como el atribuir a unos emperadores las leyes de otros. Así pues, Diocleciano, cruel perseguidor de la Iglesia, se convertiría en autor de las leyes más justas contenidas en el referido Código 5 .

En relación con el principio rescisorio consagrado en el rescripto CI.4,44,2, Ghirardi ${ }^{6}$ considera que pudo ser Triboniano quien intervino en la redacción del principio formulado en CI.4,44,2, y que solamente se dedicó a retocarlo, sin hacerlo sobre el resto de las constituciones imperiales de la época de Diocleciano.

emblemata Triboniani, GONZÁLEZ FERNÁNDEZ, R., Las estructuras ideológicas del Código de Justiniano, Murcia 1997, 45, hace alusión a las mismas, en el sentido de que ya eran así denominadas por los investigadores del Renacimiento, considerando a Triboniano como autor de los cambios, y que la investigación moderna llamaría interpolaciones.

${ }^{4}$ Sobre la creación de este Código afirma GOMEZ DE LA SERNA, P., Curso Histórico-Exegético del Derecho Romano comparado con el Español, cit., 90-93, que Justiniano nombró una comisión para compilar las constituciones imperiales, siendo encargados de esta tarea jurisconsultos como Triboniano, que debía comprender tanto las constituciones de antiguas colecciones como las que no habían sido compiladas con anterioridad, eligiendo las que estuvieran en observancia, coordinándolas y obrando con la libertad necesaria para aclarar lo que pareciere dudoso, sin poder introducir cambios en el Derecho. La nueva colección fue publicada en 7 de abril de 529 con el nombre de Código Justinianeo. En 534 Justiniano dio comisión a Triboniano de revisar el Código, encargando la agregación de las Novelas, la conciliación del Código con el Digesto y las Instituciones, y la supresión de lo que fuera superfluo o estuviera derogado. En 16 de noviembre de 534 fue confirmado el nuevo Código bajo el nombre de Repetitae praelectionis, derogándose al mismo tiempo el que le había precedido; KUNKEL, W., Historia del Derecho Romano, cit., 172-175; BONINI, R., Introduzione allo Studio dell'età giustinianea, Bologna 1989, 57-58; ANTEQUERA, J. M. ${ }^{\text {a }, ~ H i s t o r i a ~ d e ~ l a ~ l e g i s l a c i o ́ n ~ r o m a n a ~ d e s d e ~ l o s ~ t i e m p o s ~ m a ́ s ~ r e m o t o s ~}$ hasta nuestros días, Madrid 1874, 196-197.

${ }^{5}$ Cfr. MUÑOZ MALDONADO, J., Elementos de la historia del Derecho Romano, Madrid 1827, 224-225; JÖRS, P., Derecho Privado Romano, Barcelona 1965, 68-69, afirma que la nueva redacción del código en el año 534 bajo el nombre de Codex Iustinianus repetitae praelectionis, comprende las constituciones dictadas desde Adriano hasta Justiniano, siendo las más numerosas las de Diocleciano y Maximiano, introduciendo en los orígenes del Codex multitud de modificaciones; fundieron constituciones independientes, relacionadas por el contenido, y otras constituciones fueron divididas y colocadas en títulos diferentes cuando lo requería la diversidad de materias; DİAZ, E., Instituciones de Derecho Romano, I, Barcelona 1929, 206-207; BONINI, R., Introduzione allo Studio dell'età giustinianea, cit., 58.

${ }^{6}$ Cfr. GHIRARDI, J. C., La «Laesio Ultradimidium», en XIV Congreso Latinoamericano de Derecho Romano, Buenos Aires 2004, 14. 
También en el siglo XVIII fue Thomasius ${ }^{7}$ quien suscitó la duda sobre la autenticidad de los rescriptos CI.4,44,2 y CI.4,44,8, especialmente con el primero de ellos, al observar la contradicción entre este rescripto y otras leyes del mismo emperador Diocleciano que afirmaban un principio contrario al de la rescisión por laesio ultradimidium.

Un siglo más tarde Gradenwitz ${ }^{8}$ también dudó sobre la originalidad de los textos recogidos en estos dos rescriptos, en especial el texto recogido en CI.4,44,2, afirmando que era un ejemplo claro e indudable de interpolación por parte de los compiladores justinianeos. Asimismo, este mismo autor, puso de relieve que posteriormente a la época de Diocleciano no se encontraba ninguna resolución que recordase la lesión enorme, y observaba que el

${ }^{7}$ THOMASIUS, Cr., De aequitate cerebrina legis II Cod. De rescindenda venditione et eius usupractico, en Dissertationes academicae, III, 1777, 62-63; GUTIÉRREZ ALVIZ, "Laesio enormis», en Boletín de la Universidad de Granada 80, 1945, 377-378; RASCÓN GARCÍA, C., Sobre la recepción de la "laesio ultra dimidium» como causa de rescisión de los contratos en el derecho español, en Actas del II Congreso Iberoamericano de Derecho Romano, Murcia 1998, 140; MARTÍN-CASALS, M., Lesió "ultra dimidium» i equivalencia: naturalesa de la lesió $i$ àmbit d'aplicació/tesi doctoral, Barcelona 1984, 37; STANOJEVIC, O., "Laesio enormis» e contadini tardoromani, en Academia Romanistica Constantiniana. Atti VIII Convegno, Napoli 1990, 218-219; MONTAÑANA CASANÍ, A., La rescisión por lesión (origen, evolución histórica y recepción en Derecho moderno), Valencia 1999, 37; ÁLVAREZ VIGARAY, R. \& DE AYMERICH DE RENTERIA, R., La rescisión por lesión en el derecho civil español común y foral, Granada 1989, 17; LEICHT, P. S., "Laesio enormis e Justum pretium», Milano 1939, 37-38; SOLAZZI, S., L'origine storica della rescissione per lesione enorme,, en BIDR, 31 (1921) 51; ALBERTARIO, "Iustum pretium et iusta aestimatio», en BIDR, 1921,4-5; JOLOWICZ, H. F., The origin of "laesio enormis", en The juridical review, March (1937) 52; SCIUTO, P., Sulla C. D. Rescissione per Lesione Enorme, en LABEO 3 (2003) 407-408; BONFANTE, P., La data della lesione enorme, en Rivista del diritto comérciale e del diritto generale delle obbligazioni, 1921, 101; LANDUCCI, L., La lesione enorme nella compra e vendita, en Atti del R. Istituto Veneto di Scienze, Lettere ed Arti, LXXV (1916) 1201.

${ }^{8}$ GRADENWITZ, Interpolazioni e interpretazioni, en BIDR, 2 (1889) 14-15; PUGLIESE, G., Istituzioni di Diritto Romano, Padova 1988, 409; ROCA SASTRE, R. M. $^{a}$, Estudios de Derecho Privado, I, Obligaciones y Contratos, Madrid 1948, 259; VISKY, K., Appunti sulla origine Della lesione enorme, en IVRA 12 (1961) 43-45; SIRKS, A. J. B., La «laesio enormis» en Droit Romain et Byzantin, en Revue d'Histoire du droit, en Revue d'Histoire du droit LIII (1985) 291; GUTIÉRREZ ALVIZ, "Laesio enormis», en Boletín de la Universidad de Granada, cit., 378; LEICHT, P. S., "Laesio enormis e Justum pretium», cit., 37; ALBERRUCHE DÍAZ-FLORES, M. ${ }^{a}$ M., La rescisión por lesión en el derecho civil español, Madrid 2010, 38; SOLAZZI, S., L'origine storica della rescissione per lesione enorme, cit. 51; ALBERTARIO, "Iustum pretium et iusta aestimatio», cit., 4-5; JOLOWICZ, H. F., The origin of «laesio enormis, cit., 52; SCIUTO, P., Sulla C. D. Rescissione per Lesione Enorme, cit., 408; BONFANTE, P., La data della lesione enorme, cit., 101; LANDUCCI, La lesione enorme nella compra e vendita, cit., 1190-1191. 
Código Teodosiano contenía alguna decisión que excluía expresamente la posibilidad de la rescisión de la compraventa basada en el precio justo 9 .

En los textos CI.4,44,2 y CI.4,44,8, como más adelante se expondrán, observaremos como solamente se exige en ambos la existencia de la desproporción en el precio para rescindir la venta, de lo que se puede deducir que estas dos Constituciones actuaban en la práctica como regla particular, para casos concretos, y no como un principio o norma general ${ }^{10}$, pues únicamente en ambos textos encontramos la rescisión por lesión ultradimidium, y no en constituciones posteriores que ni siquiera se evidencia, pues tal como afirma Benedettini ${ }^{11}$, sería finalmente Justiniano quien la introduciría como regla general, interpolando los rescriptos CI.4,44,2 y CI.4,44,8.

No obstante la doctrina se encuentra dividida en torno a la autenticidad de los rescriptos objeto del estudio que nos ocupa; desde la corriente interpolacionista iniciada por Gradenwitz ${ }^{12}$, en que parte de la doctrina romanística se ha inclinado por la tesis de la no autenticidad de los rescriptos CI.4,44,2 y CI.4,44,8, pasando por la tendencia de afirmar la genuinidad de ambos rescriptos, y finalmente la defensa de otras posturas intermedias.

${ }^{9}$ CTh.3.1.1: IMP. CONSTANT(INUS) A. AD PROFUTURUM P(RAE)F(ECTUM) ANNONAE. Venditionis atque emptionis fidem nulla circumscriptionis violentia facta rumpi minime decet. Nec enim sola pretii vilioris querella contractus sine ulla culpa celebratus litigioso strepitu turbandus est. P(RO)P(OSITA) ID. AUG. CONSTANTINO A. V ET LICINIO C. CONSS.; GRADENWITZ, O, Interpolazioni e interpretazioni, cit., 14

${ }^{10}$ Cfr. PARRA MARTIN, M. ${ }^{a}$ D., La rescisión del contrato en los rescriptos de Diocleciano. C.4.44. "de rescindenda venditione. La laesio ultra dimidium», en Revista General de Derecho Romano, 11 (2008) 16, dice: Ciertamente, el instituto de la laesio ultradimidium, no es una regla de aplicación genérica en el siglo III d. C. Se trataría de una excepción jurídica que podía oponerse válidamente al principio general de validez del contrato libre y conscientemente celebrado; GHIRARDI, J. C., La "Laesio Ultradimidium», en XIV Congreso Latinoamericano de Derecho Romano, cit. 7, opina: «Aparece recién en el Corpus Iuris, específicamente en CI.4,44,4, como un remedio de rescindir compraventas abusivas. Pero ni aún entonces adquiere una identidad definida, ni tampoco se lo formula como regla prioritaria y relevante»; DEKKERS, R., La lésion énorme. Introduction a l'histoire des sources du droit, Paris 1937, cit., 18.

${ }^{11}$ BENEDETTINI, E., Rescissione della vendita per causa di lesione, en Archivio giurídico «Filippo Serafini», 84 (1910) 270-271.

${ }^{12}$ GRADENWITZ, O, Interpolazioni e interpretazioni, cit., 14-15; MONTANANA CASANÍ, A., La rescisión por lesión (origen, evolución histórica y recepción en Derecho moderno), cit., 38; LEICHT, P. S., «Laesio enormis e Justum pretium», cit., 37-38; ÁLVAREZ VIGARAY, R. \& DE AYMERICH DE RENTERIA, R., La rescisión por lesión en el derecho civil español común y foral, cit., 18. 


\section{PROBLEMÁTICA EXEGÉTICA DE LOS RESCRITPOS CI.4,44,2 Y CI.4,44,8 Y LA TEORÍA INTERPOLACIONISTA}

Empezaremos con la teoría interpolacionista, y concretamente sobre la respuesta dada por los emperadores Diocleciano y Maximiano en el rescripto:

\section{CI.4.44.2 Imperatores Diocletianus, Maximianus}

Rem maioris pretii si tu vel pater tuus minoris pretii, distraxit, humanum est, ut vel pretium te restituente emptoribus fundum venditum recipias auctoritate intercedente iudicis, vel, si emptor elegerit, quod deest iusto pretio recipies. Minus autem pretium esse videtur, si nec dimidia pars veri pretii soluta sit. * Diocl. et Maxim. aa. Aurelio Lupo. *'a 285 pp. V k. nov. Diocletiano a. ii et Aristobulo conss'.

De la exégesis de este texto se observa en su inicio la palabra rem como el objeto de la compraventa a rescindir, que significa cualquier cosa, pero seguidamente se refiere a un fundum venditum (fundo), por lo que plantea la duda de si la norma contenida en el rescripto era de general aplicación a todas las cosas, incluyendo los bienes muebles, o iba dirigida solamente a los bienes inmuebles ${ }^{13}$.

Ante esta duplicidad de res y fundus, Margadant sostiene que si bien la cita original se refiere a un fundus ${ }^{14}$ (término concreto) en el

${ }^{13}$ PICIRILLO, S.v.. «Rescissione», en NNDI, XV, Turín 1968, 578; FÉLIX CHAMIE, J., Rescisión por lesión enorme: el problema del origen, en Revista de Derecho Privado, en Revista de Derecho Privado, 19 (2010) 28; DEKKERS, R., La lésion énorme, Introduction a l'histoire des sources du droit, Paris 1937, 16; KLAMI H. T., "Laesio enormis» in Roman Law, en LABEO 33 (1987)55; MARTÍN-CASALS, M., Lesió «ultra dimidium» i equivalencia: naturalesa de la lesió $i$ àmbit d'aplicació/tesi doctoral, cit., 32; FÉLIX CHAMIE, J., Rescisión por lesión enorme: el problema del origen, en RDP, cit., 28; vid. ÁLVAREZ VIGARAY, R. \& AYMERICH DE RENTERÍA,, R., cit, 16-17; STANOJEVIC, O., "Laesio enormis» e contadini tardoromani, en Academia Romanistica Constantiniana, cit., 219.

${ }^{14} \mathrm{Vid}$. MARGADANT, G. F., La historia de la»laesio enormis»como fuente de sugerencias para la legislación moderna, en Boletín Mexicano de derecho comparado, cit. 36; Vid. ÁLVAREZ VIGARAY, R. \& AYMERICH DE RENTERÍA,, R., cit, 23, ambos autores consideran que las constituciones de Justiniano sobre la rescisión por lesión utradimidium fueron desenvueltas en el Imperio romano de Oriente, resaltando el texto griego de las Basílicas para eliminar las dudas planteadas sobre si se aplicaba a la venta de todas las cosas o sólo a la de los fundos, traduciendo ambas palabras rem y fundum por la palabra griega pragma, que significa cosa; DEKKERS, R., La lésion énorme, Introduction a l'histoire des sources du droit, cit., 38; SIRKS, A. J. B., La «laesio enormis» en Droit Romain et Byzantin, en Revue d'Histoire du droit, cit., 294. LEICHT, P. S., "Laesio enormis e Justum pretium», cit., 40; SOLAZZI, S., L'origine storica della rescissione per lesione enorme, cit., 73 y GENZMER, E., Die antiken Grundlagen der Lehre vom gerechten Preis und der "laesio enormis», 57, consideran que la frase «Rem maioris pretii» era fruto de los compiladores, y que «fundum» pertenecería a la frase genuina. 
que probablemente Diocleciano utilizaría únicamente para la venta de un inmueble, Justiniano la extendería a toda la res $^{15}$ (término general y abstracto), y la aplicaría como regla general a la venta de cualquier $\operatorname{cosa}^{16}$, ya se tratasen de bienes muebles o inmuebles, idea que quedaría confirmada por el derecho bizantino postjustinianeo, en Basílicas 19.2, que utilizaba la palabra pragma y en un sentido general significa cosa ${ }^{17}$.

Continuando con el análisis del citado rescripto la expresión humanum est, podría estar relacionada con la doctrina cristiana ${ }^{18}$, ejerciendo su influencia en la legislación imperial postclásica ${ }^{19}$, y pudiendo ser una interpolación de la legislación justinianea ${ }^{20}$. En la frase $u t$ vel... fundum venditum recipias, vel ... quod deest justo pretio recipies,

${ }^{15}$ GARCÍA SÁNCHEZ, J. \& GARCÍA FUEYO, B, «Naturaliter circumvenire de pretio». La doctrina jurídica salmantina del siglo XVI, en IX Congreso Internacional XII Iberoameriacano de Derecho Romano, cit., 351.

${ }^{16}$ DEKKERS, R., La lésion énorme. Introduction a l'histoire des sources du droit, cit., 23; SOLAZZI, S., L'origine storica della rescissione per lesione enorme, cit., 73, este autor considera que la frase rem maioris pretii fue interpolada y considera que fundum se trata de una palabra original.

${ }_{17}$ PICIRILLO, S.v. "Rescissione», cit., 578; MARGADANT, G. F., La historia de la»laesio enormis»como fuente de sugerencias para la legislación moderna, en Boletín Mexicano de derecho comparado 10 (1977) 36.

${ }^{18} \mathrm{Al}$ margen de esta consideración, PALMA, A., Humanior interpretatio. 'Humanitas' nell'interpretazione e nella normazione da Adriano ai Severi, Torino, 1992, 152, es de la opinión que, es posible encontrar en la cultura jurídica del siglo III valores jurídicos que permitirían al jurista actualizar y superar los institutos del ius civile; asimismo, la humanitas podría calificarse como un standard, basado en conceptos metajurídicos que operarían en la realidad social; Sobre la humanitas como valor moral, SENECA, Ep. 88.30: "Il senso di umanità ci impedisce di essere superbi e sgarbati con il prossimo; nelle parole, nelle azioni, nei sentimenti si mostra cortese e disponibile con tutti; fa suoi i mali degli altri e ama il suo bene soprattutto quando può essere un bene per gli altri. Gli studi liberali ci insegnano forse un simile comportamento? No, e non ci insegnano la semplicità, la modestia, la moderazione e neppure la frugalità e la parsimonia, né la clemenza che risparmia il sangue altrui como se fosse il propio e sa che l'uomo non deve abusare di un suo simile.» Se trata, pues, de una virtud que veta la soberbia en las relaciones sociales, veta la avaricia, el egoísmo, e impone respecto de todos un comportamiento amable y cordial en las palabras, en las acciones y en los sentimientos.

${ }^{19} \mathrm{Vid}$. GARCÍA SÁNCHEZ, J. \& GARCÍA FUEYO, B, «Naturaliter circumvenire de pretio». La doctrina jurídica salmantina del siglo XVI, en IX Congreso Internacional XII Iberoameriacano de Derecho Romano, en IX Congreso Internacional XII Iberoameriacano de Derecho Romano, I, Las Palmas de Gran Canaria 2007, 351; SOLAZZI, S., L'origine storica della rescissione per lesione enorme, cit., 73; LEICHT, P. S., "Laesio enormis e Justum pretium», cit., 39.

${ }^{20}$ LEICHT, P. S., "Laesio enormis e Justum pretium», cit., 39; oposición contraria es la de FÉLIX CHAMIE, J., Rescisión por lesión enorme: el problema del origen, en RDP, cit., 28-29; Vid. DEKKERS, R., La lésion énorme. Introduction a l'histoire des sources du droit, cit., 18; ALBERTARIO, E., Studi di Diritto Romano, V, Milano, 1937, $610 \mathrm{n} 1$. 
se repite el mismo verbo recipias y recipies y, en opinión de García Vallés ${ }^{21}$, si el rescripto hubiese sido redactado de una sola vez, hubiera bastado uno de los dos verbos. Asimismo y a pesar que estos dos verbos dependen de $u t$, no concuerdan entre ellos, ya que el verbo recipias corresponde al modo subjuntivo, mientras que recipies pertenece al tiempo futuro del modo indicativo ${ }^{22}$. Dékkérs destaca que recipies no concuerda con $u t$, que la solución sobre la opción del comprador recogida en quod deest justo preti recipies parece ajena a la solución original de recobrar el fundo restituyendo el precio a los compradores, que sería ignorada por Diocleciano ${ }^{23}$.

Siguiendo el texto objeto de este estudio ut vel pretium te restituente emptoribus, al restituir el vendedor el precio a la otra parte contratante utiliza en plural el vocablo emptoribus (varios compradores), pero más adelante, para el comprador tras completar el justo precio y así evitar la rescisión de la venta, prosigue en singular cuando utiliza las palabras si emptor eligerit ${ }^{24}$, y por este motivo podría considerarse interpolado el vocablo emptor. Asimismo, al hablarse primero de varios compradores y después al singularizarse en un solo, podría derivarse de la intención de los compiladores de abandonar el caso en concreto y establecer una regla general ${ }^{25}$.

${ }^{21}$ Cfr., GARCÍA VALLÉS, R., Rescisión por "laesio ultradimidium», Barcelona, 1962, 13; HACKL, K., Zu den Wurzlen der Anfechtung wegen "laesio enormis», » en ZSS 98 (1981) 152 y ss.

${ }^{22}$ FÉLIX CHAMIE, J., Rescisión por lesión enorme: el problema del origen, en Revista de Derecho Privado, cit., 28; STANOJEVIC, O., "Laesio enormis» e contadini tardoromani, en Academia Romanistica Constantiniana, cit. 219-220; SOLAZZI, S., L'origine storica della rescissione per lesione enorme, cit., 73.

${ }^{23}$ Vid. DEKKERS, R., La lésion énorme. Introduction a l'histoire des sources du droit, cit., 24.

${ }^{24}$ Vid. DEKKERS, R., La lésion énorme. Introduction a l'histoire des sources du droit, 17; GARCÍA VALLÉS, R., Rescisión por "laesio ultradimidium», cit., 13; GHIRARDI, J. C. \& FILIPPI DE GHIRARDI, M. C., La «laesio ultradimidium», en Revista General del Derecho, ", en Revista General de Derecho Romano, 13 (2009) 6; FÉLIX CHAMIE, J., Rescisión por lesión enorme: el problema del origen, en RDP, cit., 28; SIRKS, A. J. B., La «laesio enormis» en Droit Romain et Byzantin, en Revue d'Histoire du droit, cit., 294; ZIMMERMANN, R., The law of obligations, New York 1996, 260; MARTÍN-CASALS, M., Lesió "ultra dimidium» $i$ equivalencia: naturalesa de la lesió $i$ àmbit d'aplicació/tesi doctoral, Barcelona 1984, cit., 34; SOLAZZI, S., L'origine storica della rescissione per lesione enorme, cit., 73.

${ }^{25}$ BRASLOFF, S., Zur Lehre von der laesio enormis in byzantinischen Recht en Zeitschrift für leichende Rechtswissenschaft 27 (1912) 262; MONTAÑANA CASANÍ, A., La rescisión por lesión (origen, evolución histórica y recepción en Derecho moderno), cit., 40; sobre esta medida de carácter excepcional adoptada en el rescripto CI.4,44,2, LEICHT, P. S., "Laesio enormis e Justum pretium», cit., 39 considera que la misma quedaría justificada por el hecho de que el beneficio se concedía al hijo del vendedor lesionado. Asimismo tampoco era lógico ni justo que del examen de un caso concreto se dedujera una regla general, a pesar de que en el Derecho Romano era práctica 
Sobre esta facultad dejada al comprador de restituir o de suplir lo que falte para alcanzar el justo precio, opina GARCÍA VALLÉS ${ }^{26}$ que en CTh.3,1,4 del año 383 ya era conocida:

CTh 3,1,4: «Imppp. Grat., Valentin. et Theodos. aaa. ad Hypatium pf. $p$. quisquis maior aetate atque administrandis familiarum suarum curis idoneus comprobatus praedia, etiam procul posita, distraxerit, etiamsi praedii forte totius quolibet casu minime facta distractio est, repetitionis in reliquum, pretii nomine vilioris, copiam minime consequatur.neque inanibus immorari sinatur obiectis, ut vires sibimet locorum causetur incognitas, qui familiares rei scire vires vel merita atque emolumenta debuerit. dat. vi. non. Mai. Mediolano, Merobaude II. et Saturnino coss.

En este texto se aprecia que si una persona mayor de edad y capaz de administrar su patrimonio ha vendido terrenos que se encuentren a gran distancia, inclusive si la venta se ha hecho por un precio muy bajo, no debe tener la facultad de pedir el excedente del precio con el argumento de que el precio recibido haya sido muy bajo. Ello significa que este pasaje, cuando nombra la facultad de pedir el excedente del precio, lleva implícita la idea del complemento del precio, con lo cual cabría la posibilidad de que la misma fuese incorporada al rescripto CI.4,44,2, ya conocido en el año 383, y que posiblemente hubiera sido interpolado.

Sobre esta línea de interpretación Justiniano podría haberse inspirado en una regla de derecho clásico basada en los contratos de buena fe que permitiera a las partes rectificar el precio fijado en un engaño.

frecuente con otras instituciones; GHIRARDI, J. C., La "Laesio Ultradimidium», en XIV Congreso Latinoamericano de Derecho Romano, cit., 12, opina este autor que resulta extraño que en el rescripto se autorizase a un hijo rescindir una compraventa realizada por el padre, y que si bien en el texto original se introdujeron varias modificaciones, no toda la constitución se redactó al mismo tiempo, por lo que su origen llegaría a ser justinianeo; GHIRARDI, J. C. \& FILIPPI DE GHIRARDI, M. C., La «laesio ultradimidium», en Revista General del Derecho, cit., 7; DEKKERS, R., La lésion énorme. Introduction a l'histoire des sources du droit, cit., 18; PARRA MARTIN, M. ${ }^{a}$ D., La rescisión del contrato en los rescriptos de Diocleciano. C.4.44. "de rescindenda venditione. La laesio ultra dimidium", en Revista General de Derecho Romano, cit., 8; KLAMI H. T., «Laesio enormis» in Roman Law, cit., 55; cfr. GARCÍA VALLÉS, R., Rescisión por «laesio ultradimidium», cit. 14, dice: "Éste es un favor difícil de imaginar bajo el reinado de Diocleciano y los propios sucesores de este príncipe, Arcadio y Honorio confirman aún esta regla: "actio ab haredere incipere non potest» (C. Th. 3, 1, de Cont, empt.7; 1 y 2, de div. Resc. 8)»; MARTÍN-CASALS, M., Lesió «ultra dimidium» i equivalencia: naturalesa de la lesió $i$ àmbit d'aplicacióltesi doctoral, Barcelona 1984, cit., 33.

${ }^{26}$ Vid. GARCÍA VALLÉS, R., cit. 16-17. 
Esta regla podemos encontrarla en:

D.19,1,13,4 Ulpianus libro 32 ad edictum.

Si venditor dolo fecerit, ut rem pluris venderet, puta de artificio mentitus est aut de peculio, empti eum iudicio teneri, ut praestaret emptori, quanto pluris servum emisset, si ita peculiatus esset vel eo artificio instructus.

En este pasaje observamos que si el vendedor obrase con dolo para vender más cara la cosa -por ejemplo, si mintió respecto al oficio o respecto al peculio- se obliga por la acción de compra a entregar al comprador cuanto por más hubiese comprado el esclavo, si hubiese tenido tal peculio, o hubiese estado instruido en aquel oficio. Debería, pues, devolver al comprador el excedente obtenido con la venta basada en un engaño.

Volviendo nuevamente al análisis del rescripto CI.4,44,2 en la frase auctoritate intercedente judicis, Dékkérs ${ }^{27}$ opina que la auctoritas judicis no tiene ningún sentido situarla en la época de Diocleciano, pues el derecho clásico conocía l'arbitrium, l'officium, pero no la autoridad del juez. Solamente el rescripto CI.4,44,2 se remite a la intervención de la autoridad judicial para resolver la cuestión que se plantea, y luego no aparece en ninguna constitución posterior ${ }^{28}$. Pues no siempre sería necesaria la intervención de la autoridad del juez, ya que el vendedor no llamaría a juicio al comprador que aceptase buenamente rescindir el contrato o pagar el suplemento del precio. Considera que el texto original CI.4,44,2 requeriría la auctoritas de un magistrado si, hipotéticamente, hubiese admitido la restitutio in integrum, y que los compiladores habrían sustituido la palabra magistrado por la de iudicis ${ }^{29}$.

También observamos como en las frases quod deest iusto pretio recipies y si nec dimidia pars veri pretii soluta sit, las palabras iusto pretio y veri pretii se utilizan indistintamente, por lo que también se aprecian indicios de interpolación ${ }^{30}$. Asimismo llama la atención el hecho de que al principio del rescripto CI.4,44,2 se defina de una manera imprecisa el minoris pretii en relación con el veri pretii, y que después prosiga el texto dando definición al precio en relación

${ }^{27}$ Vid. DEKKERS, R., La lésion énorme. Introduction a l'histoire des sources du droit, cit., 25; MONTAÑANA CASANÍ, A., La rescisión por lesión (origen, evolución histórica y recepción en Derecho moderno), cit., 59-60.

${ }^{28}$ SCIUTO, P., Sulla C. D. Rescissione per Lesione Enorme, cit., 406.

${ }^{29}$ SOLAZZI, S., L'origine storica della rescissione per lesione enorme, cit., 76.

${ }^{30}$ BRASLOFF, S., Zur Lehre von der laesio enormis in byzantinischen Recht, cit., 263; SOLAZZI, S., L'origine storica della rescissione per lesione enorme, cit., 74. 
con el iusto pretio $^{31}$. La rescisión por lesión podría estar relacionada con el concepto de iustum pretium, concepto que no sería conocido en la época clásica ${ }^{32}$ y que llegaría a desarrollarse en la etapa postclásica, y tendría un reconocimiento general en el derecho justinianeo ${ }^{33}$; la expresión iustum pretium casi siempre se encuentra interpolada en las fuentes, y por lo tanto la lesión enorme sería introducida en el Código de Justiniano por la actividad interpolacionista de aquella época ${ }^{34}$.

En la última frase del rescripto: Minus autem pretium esse videtur, si nec dimidia pars veri pretii soluta sit, se refiere a que el precio de la venta sería menor, si no se hubiera pagado la mitad del verdadero precio de la cosa, sin embargo en todo el rescripto se habla del minoris pretii de la venta sin hacer alusión si ese precio sería inferior al justo precio de la cosa o sería inferior a la mitad del mismo, pues la distinción en la mitad es la que justificaría la rescisión, y por lo tanto hubiera sido conveniente mencionarla ${ }^{35}$, puesto que fijar la medida de

${ }^{31}$ Vid. MONTAÑANA CASANÍ, A., La rescisión por lesión (origen, evolución histórica y recepción en Derecho moderno), cit., 51.

${ }^{32}$ Sobre la autenticidad del rescripto CI.4,44,2 en relación con el precio justo, merece tener en cuenta el principio del derecho clásico sobre la libertad en la fijación del precio que consta en el pasaje recogido en D.4,4,16,4: Ulpianus 11 ad ed. Idem Pomponius ait in pretio emptionis et venditionis naturaliter licere contrahentibus se circumvenire. Este texto dice que en una compraventa es lícito por parte de los contratantes engañarse con el precio, lo que supondría que si el comprador celebra una compraventa en condiciones más favorables que el vendedor, el contrato no debe rescindirse, pues el engaño sobre el precio no presupone ningún tipo de lesión.

${ }^{33}$ Sobre el origen compilatoria del justo precio en los rescriptos CI.4,44,2 y CI.4,44,8 que dieron origen a la lesión enorme, ALBERTARIO E., Studi di Diritto Romano, v. III, Milano, 1936, 408-409.

${ }^{34}$ ALBERTARIO, Iustum pretium et iusta aestimatio, cit., 16-17; GUTIÉRREZ ALVIZ, «Laesio enormis», cit., 385; LEICHT, P. S., "Laesio enormis e Justum pretium», cit., 38; RASCÓN GARCÍA, C., Sobre la recepción de la «laesio ultra dimidium» como causa de rescisión de los contratos en el derecho español, cit., 140; MARTÍN-CASALS, M., Lesió "ultra dimidium» i equivalencia: naturalesa de la lesió $i$ àmbit d'aplicació/tesi doctoral, Barcelona 1984, cit., 34; SOLAZZI, S., L'origine storica della rescissione per lesione enorme, cit., 75; SCIUTO, P., Sulla C. D. Rescissione per Lesione Enorme, cit., 408; MARGADANT, G. F., La historia de la»laesio enormis»como fuente de sugerencias para la legislación moderna, cit., 37; GOMEZ ACEBO, F., Revisión del concepto de lesión; su estructura técnica, en Revista de Derecho Privado, XXXIV (1950) 497; GARCIA GARCIA, A. \& ALONSO RODRÍGUEZ, B., El pensamiento económico y e mundo del derecho hasta el siglo XVI, en El pensamiento económico en la escuela de Salaman$c a$, Salamanca 1998, 68, ambos autores consideran interpolados los dos rescriptos atribuidos a Diocleciano y Maximiano, CI.4,44,2 y CI.4,44,8, en la medida que la laesio enormis, viene a limitar la plena libertad contractual de las partes para el establecimiento del precio.

${ }^{35}$ Vid. GARCÍA VALLÉS, R., Rescisión por «laesio ultradimidium», cit., 13; DEKKERS, R., La lésion énorme. Introduction a l'histoire des sources du droit, cit., 17; GARCÍA SÁNCHEZ, J., La «laesio enormis» y el precio de la subasta, en Actas del II 
la desproporción significaría establecer con certeza cuándo la lesión se considera enorme. Podemos decir que esta frase estaría mal expresada, pues está claro que un precio bajo siempre será menor que el precio justo, sea cual sea su diferencia; además, en este texto la dimidia pars se constituye como un criterio que habría tenido la función de una presunción de dolo, es decir, como un instrumento puesto a disposición para dar relevancia a la lesión, en el sentido de determinar un dolo irrelevante cuando se tratase de una desequilibrio mínimo, y un dolo sancionable, cuando la entidad de la desproporción fuese considerable ${ }^{36}$.

Asimismo las incorrecciones gramaticales y su difícil armonización con otros textos del Codex Theodosianus llegarían a demostrar la interpolación del texto ${ }^{37}$. Un ejemplo de evidente contradicción lo hallamos en CI.4,44,4, constitución de Diocleciano y Maximiano, dirigida a Eudoxio, en un año entre el 293 y 304 d J. C., que dice:

CI.4.44.4

Imperatores Diocletianus, Maximianus. Ad rescindendam venditionem et malae fidei probationem hoc solum non sufficit, quod magno

Congreso Iberoamericano de Derecho Romano, Oviedo 1998, 121; STANOJEVIC, O., "Laesio enormis» e contadini tardoromani, en Academia Romanistica Constantiniana, cit., 219; MONTAÑANA CASANÍ, A., La rescisión por lesión (origen, evolución histórica y recepción en Derecho moderno), cit., 39; BENEDETTINI, E., Rescissione della vendita per causa di lesione, cit., 270-271.

${ }^{36}$ FELIX CHAMIE, J., Rescisión por lesión enorme: el problema del origen, cit., 33, dice que: «De esta manera, puede también pensarse que el instituto de la lesión habría sido introducido como expediente para superar las incertezas de la doctrina del dolo, en un momento histórico caracterizado por una difundida necesidad de tutela de las clases menos favorecidas, expuestas a cotidianos abusos».

${ }^{37} \mathrm{Vid}$. ZIMMERMANN, R., The law of obligations, cit., 259-260; MARGADANT, G. F., cit., 32-33. ARANGIO-RUIZ, V., cit. 144-146; OBARRIO MORENO, A., La laesio enormis y su recepción, en Actas del II Congreso Iberoamericano de Derecho Romano, 1998,111; Sobre las irregularidades gramaticales el autor KUNKEL, W., Historia del Derecho Romano, Barcelona 1970, cit., 181, expone: «Muchas irregularidades gramaticales o estilísticas, que antes se aducían como prueba de interpolaciones sustanciales, se pueden explicar de un modo más plausible como originadas por el resumen del texto, por su reelaboración formal o por defectos de la tradición manuscrita (antes o después de Justiniano)»; GONZÁLEZ FERNÁNDEZ, R., Las estructuras ideológicas del Código de Justiniano, Murcia 1997, 45-46: Sobre contradicciones textuales vid. vid. KASER, M., Las interpolaciones en las fuentes jurídicas romanas, cit., 77-79; RASCÓN GARCÍA, C., Sobre la recepción de la "laesio ultra dimidium» como causa de rescisión de los contratos en el derecho español, cit., 140; SOLAZZI, S., L'origine storica della rescissione per lesione enorme, 51 y ss.; MONTAÑANA CASANÍ, A., La rescisión por lesión (origen, evolución histórica y recepción en Derecho moderno), cit., 41; GHIRARDI, J. C., La "Laesio Ultradimidium», en XIV Congreso Latinoamericano de Derecho Romano, cit., 11-12; Cfr. GARCÍA VALLÉS, R., cit. 12, dice este autor: «que las frases son un poco inconexas y que el texto es de tan difícil traducción, que se hace intraducible». 
pretio fundum comparatum minoris distractum esse commemoras. * Diocl. et Maxim. aa. et cc. Sempronio Eudoxio. *'a 293 d. non. april. Byzantio aa. conss'.

Este texto viene a significar que para la rescisión de la venta y para la prueba de la mala fe no basta solamente que el fundo comprado por elevado precio haya sido vendido por otro menor; ya no basta la existencia de una diferencia de precios de cierta magnitud, sino que se introduce un nuevo elemento de naturaleza subjetiva, basado en la necesidad de probar la mala fe de la contraparte, con lo cual y en contraste con lo dispuesto en CI.4,44,2, la lesión dejaría de ser meramente objetiva. Asimismo el texto CI.4,44,4 se vería reforzado por CTh.3,1,138 del año 319 d. J. C., CTh.3,1,739 del año 396 d. J. C. y CTh.14,3, $1^{40}$.

Asimismo Dékkers ${ }^{41}$ considera que el rescripto CI.4,44,2 fue interpolado por los compiladores justinianeos, ya que la condición y límite de la rescisión por lesión fijada en la mitad del justo precio no era conocida en tiempos de Diocleciano, pues la legislación de aquella época era opuesta al contenido del rescripto ${ }^{42}$. Y ello quedaría demostrado en el siguiente pasaje del rescripto CI.4,44,15,

${ }^{38}$ CTh.3,1,1 IMP. CONSTANT(INUS) A. AD PROFUTURUM P(RAE)F(ECTUM) ANNONAE. Venditionis atque emptionis fidem nulla circumscriptionis violentia facta rumpi minime decet. Nec enim sola pretii vilioris querella contractus sine ulla culpa celebratus litigioso strepitu turbandus est. P(RO)P(OSITA) ID. AUG. CONSTANTINO A. V ET LICINIO C. CONSS.

${ }^{39}$ CTh.3,1,7 IDEM AAA. REMIGIO P(RAE)F(ECTO) AUG(USTALI). Semel inter personas legitimas initus empti contractus et venditi ob minorem adnumeratam pretii quantitatem nequeat infirmari. DAT. III KAL. APRIL. CONSTANT(INO)P(OLI) ARCAD(IO) A. IIII ET HONOR(IO) A. III CONSS.

${ }^{40}$ CTh.14,3,1 Imp. Constantinus a. ad profuturum praefectum annonae. Cunctis pistoribus intimari oportet, quod, si quis forte possessiones suas ideo putaverit in alios transferendas, ut postea se, rebus in abdito collocatis, minus idoneum adseveret, tamquam in locum eius alio subrogando, nihil ei haec astutia nec detestabilia commenta profutura sunt, sed in obsequio pistrini sine ulla excusatione durabit nec ad eius iura revocabuntur, si quas emptiones transcripserit. Proposita id. Aug. Constantino a. V et Licinio Ccaes. conss. (319 Aug. 13).

${ }^{41}$ Vid. DEKKERS, R., La lésion énorme. Introduction a l'histoire des sources du droit, cit., 18-19; También ARANGIO RUIZ, V., cit., 145-146, quien afirma que en el año 383 la rescisión por lesión no existía, ni siquiera era conocida en la época de la promulgación del Código Teodosiano del año 439; JOLOWICZ, H. F., The origin of «laesio enormis», cit., 51.

${ }^{42}$ En esta misma línea de interpretación, GIRARD, P. F., Manuel élémentaire de droit romain, 1906, 540, cuando dice que antiguamente no era necesario que el precio fuera justo, sin embargo una reforma que el Código de Justiniano atribuyó a las constituciones de Diocleciano, CI.4,44,2 y CI. 4,44,8, permitió atacar la venta por causa de lesión en más de la mitad del precio justo. 


\section{CI.4.44.15}

Imperatores Gratianus, Valentinianus, Theodosius. Quisquis maior aetate praedia etiam procul posita distraxerit, paulo vilioris pretii nomine repetitionis rei venditae copiam minime consequatur. neque inanibus immorari sinatur obiectis, ut vires sibimet locorum causetur incognitas, qui familiaris rei scire vires vel merita atque emolumenta debuerat. * Grat. Valentin. et Theodos. aaa. ad Hypatium pp. *'a 383 d. VI non. mai. Mediolani Merobaude ii et Saturnino conss'.

En este texto se dice que ningún mayor de edad que hubiere enajenado predios, aunque situados lejos, consiga de ninguna manera facultad para la repetición de la cosa vendida, por razón de haber sido el precio un poco bajo. Porque no se deja que se pierda tiempo en baldíos propósitos, para que se disculpe a sí mismo de no haber conocido el valor de los bienes familiares, o sus méritos y sus emolumentos. Concretamente en la frase «...paulo vilioris pretii nomine repetitionis rei venditae copiam minime consequatur», al decir que el precio de la compraventa ha sido "paulo vilioris pretii nomine», un precio un poco bajo, no le sirve de base al comprador para entablar una acción de rescisión ${ }^{43}$. Observamos nuevamente que el precio inferior, como elemento objetivo, no es por si solo causa suficiente para rescindir la compra.

Un criterio similar podemos encontrar en el texto CTh.3,1,4, que hemos analizado con anterioridad, en donde observamos en la frase: «...comprobatus praedia, etiam procul posita, distraxerit, etiamsi praedii forte totius quolibet casu minime facta distractio est, repetitionis in reliquum, pretii nomine vilioris, copiam minime consequatur...» que se le niega la acción de rescisión al vendedor bajo el argumento «pretii nomine vilioris», basado en el precio bajo; asimismo podemos comprobar que aquí no aparece el vocablo "paulo» como en CI.4,44,15 "paulo vilioris pretii nomine», precio un poco bajo, que con el uso de "paulo» evidenciaría su interpolación ${ }^{44}$. En opinión de

${ }^{43}$ Vid. MARGADANT, G. M., La historia de la»laesio enormis»como fuente de sugerencias para la legislación moderna, en Boletín Mexicano de derecho comparado, cit. 35; FÉLIX CHAMIE, J., Rescisión por lesión enorme: el problema del origen, en Revista de Derecho Privado, cit. 25; VOLTERRA, E., Istituzioni di Diritto Privato Romano, Roma 1961, 501.

${ }^{44}$ Vid. MARGADANT, G. M., La historia de la»laesio enormis»como fuente de sugerencias para la legislación moderna, en Boletín Mexicano de derecho comparado, cit. 35. También vid. ARANGIO RUIZ, V., La compravendita in Diritto Romano, cit., 145-146. Afirma este autor que en el año 383 la rescisión por lesión no existía, ni siquiera era conocida en la época de la promulgación del Código Teodosiano del año 439; FÉLIX CHAMIE, J., Rescisión por lesión enorme: el problema del origen, en Revista de Derecho Privado, cit., 25; VOLTERRA, E., Istituzioni di Diritto Privato Romano, cit., 501; OBARRIO MORENO, A., La laesio enormis y su recepción, en Actas del II Congreso Ibe- 
Gradenwitz ${ }^{45}$ la palabra paulo sería una adición postclásica o justinianea, lo cual significa que su inclusión en un texto supondría su interpolación, y demostraría que la laesio enormis sería de origen justinianeo.

Y también en la constitución:

\section{CI.4.44.12}

Imperatores Diocletianus, Maximianus. Non idcirco minus venditio fundi, quod hunc ad munus sumptibus necessariis urguentibus non vilioris pretii vel urguente debito te distraxisse contendis, rata manere debet. illicitis itaque petitionibus abstinendo ac pretium, si non integrum solutum est, petendo facies consultius. * Diocl. et Maxim. aa. et cc. Antiocho. *

En este texto se dice que no debe quedar siendo menos válida la venta de un fundo al venderse por un menor precio, porque era necesario sufragar los gastos de un cargo o porque la deuda fuese urgente, no siendo por ello motivo para rescindir la venta; por lo aquí observamos nuevamente que por el simple hecho de que el precio de la venta sea bajo no sirve para pedir su rescisión.

De la exégesis de los textos Cth.3,1,1, Cth.3,1,4, Cth.3,1,7, Cth.14.3.1, CI.4,44,4, CI.4,44,12 y CI.4,44,15, podemos decir que originariamente los rescriptos CI.4,44,2 y CI.4,44,8 podrían haber sido concebidos sin hacer referencia a la mitad del precio justo, pues de haber sido redactados en época de Diocleciano, hubiera sido recogido este principio por los compiladores teodosianos y legislación postclásica.

Ahora procederemos al análisis de la constitución CI.4,44,8 que trata de un rescripto de Diocleciano y Maximiano dirigido a Evodia, que dice:

$$
\text { CI.4.44.8 }
$$

Imperatores Diocletianus, Maximianus. Si voluntate tua fundum tuum filius tuus venumdedit, dolus ex calliditate atque insidiis emptoris

\footnotetext{
roamericano de Derecho Romano, cit., 111; DEKKERS, R., La lésion énorme. Introduction a l'histoire des sources $d u$ droit, cit., 21, afirma que los compiladores de Justiniano en lugar de poner vilioris pretii del texto primitivo, que regula toda lesión, pondrían Paulo vilioris pretii, para distinguir la lesión módica de la enorme, SIRKS, A. J. B., La "laesio enormis» en Droit Romain et Byzantin, en Revue d'Histoire du droit, cit., 295; GUTIÉRREZ ALVIZ, "Laesio enormis», en Boletín de la Universidad de Granada, cit., 387; JOLOWICZ, H. F., The origin of «laesio enormis», cit., 71.

${ }^{45}$ GRADENWITZ, O, Interpolazioni e interpretazioni, cit., 14-15, opina que esta adición no tendría sentido más que con la introducción del concepto de laesio enormis después del Cth.3,1,4; SIRKS, A. J. B., La «laesio enormis» en Droit Romain et Byzantin, en Revue d'Histoire du droit, cit., 295; RICCOBONO, S., Scritti di Diritto Romano, I, Palermo 1957, 373; MONTAÑANA CASANÍ, A., La rescisión por lesión (origen, evolución histórica y recepción en Derecho moderno), cit., 39.
} 
argui debet vel metus mortis vel cruciatus corporis imminens detegi, ne habeatur rata venditio. Hoc enim solum, quod Paulo minori pretio fundum venumdatum significas, ad rescindendam emptionem invalidum est. Quod videlicet si contractus emptionis atque venditionis cogitasses substantiam et quod emptor viliori comparandi, venditor cariori distrahendi votum gerentes ad hunc contractum accedant vixque post multas contentiones, paulatim venditore de eo quod petierat detrahente, emptore autem huic quod obtulerat addente, ad certum consentiant pretium, profecto perspiceres neque bonam fidem, quae emptionis atque venditionis conventionem tuetur, pati neque ullam rationem concedere rescindi propter hoc consensu finitum contractum vel statim vel post pretii quantitatis disceptationem: nisi minus dimidia iusti pretii, quod fuerat tempore venditionis, datum est, electione iam emptori praestita servanda. * Diocl. et Maxim. aa. et cc. Aureliae Euodiae. *' 'a 293 d. k. dec. aa. conss'.

En el primer periodo «Si voluntate..., ne habeatur rata venditio» se expone que si un hijo vendió un fundo de su padre, se debe probar el dolo o fraude del comprador, o demostrar amenaza de muerte o inminente tortura corporal, para rescindir una venta. A tenor de la frase siguiente: «Hoc enim solum,...ad rescindendam venditionem invalidum est», el fundo que fue vendido por un precio menor no es suficiente para rescindir la venta. Pues para conseguir la rescisión de una venta es preciso la existencia de dolo o violencia, no siendo suficiente que el precio por el que fue vendido el fundo sea bajo ${ }^{46}$. También en esta última frase vemos que aparece la palabra «Paulo» como prueba de que este texto llegó a ser interpolado ${ }^{47}$.

Observamos que en la mayor parte del pasaje prevalece la voluntad contractual como regla general de la compraventa ${ }^{48}$, así pues dice Quod videlicet si contractus emptionis atque venditionis cogitasses substantiam et quod emptor viliori comparandi, venditor cariori distrahendi votum gerentes ad hunc contractum accedant vixque post multas contentiones, paulatim venditore de eo quod petierat detrahente, emptore autem huic quod obtulerat addente, ad certum consentiant pretium, profecto perspiceres neque bonam fidem, quae emptionis atque $v$ enditionis conventionem tuetur, pati neque ullam rationem concedere rescindi propter hoc consensu finitum contractum vel statim vel post pretii

${ }^{46}$ DEKKERS, R., La lésion énorme. Introduction a l'histoire des sources du droit, cit., 22; VISKY, K., Appunti sulla origine Della lesione enorme, cit., 43.

${ }^{47}$ Vid. MARGADANT, G. M., La historia de la»laesio enormis»como fuente de sugerencias para la legislación moderna, en Boletín Mexicano de derecho comparado, cit. 35. Vid. también ARANGIO RUIZ, V., cit., 146-147; FÉLIX CHAMIE, J., Rescisión por lesión enorme: el problema del origen, en Revista de Derecho Privado, cit., 31; SIRKS, A. J. B., La «laesio enormis» en Droit Romain et Byzantin, en Revue d'Histoire du droit, cit., 295.

${ }^{48}$ VISKY, K., Appunti sulla origine Della lesione enorme, cit., 43. 
quantitatis disceptationem, por lo que se permite como principio o esencia del contrato de compraventa que el comprador compre por menos y que el vendedor venda más caro, e incluso el vendedor rebaje el precio y el comprador ofrezca pagar más, y no por convenir libremente las partes un precio se rescinda el contrato. Apreciamos, pues el principio clásico de la autonomía de la voluntad de las partes en la fijación del precio ${ }^{49}$.

Este mismo rescripto se termina repentinamente con la frase: «... nisi minus dimidia iusti pretii, quod fuerat tempore venditionis, datum $e s t, \ldots »$ que dice a no ser que se haya dado menos de la mitad del justo precio al tiempo de la venta (principio distinto al de la autonomía de la voluntad), lo que en opinión de Fernández de Buján, F. desvirtúa el principio basado en la libertad contractual como regla general, pudiendo tratarse de un añadido que no se correspondería con el texto original $^{50}$, y que lleva implícita la rescisión del contrato de compra-

${ }^{49} \mathrm{El}$ comportamiento de la jurisprudencia clásica respecto a la determinación del precio era de dejarla al juego de la oferta y la demanda, destacando como pasajes en materia del principio «naturalitier se circumscribere, en D.4,4,16,4 Ulpianus libro undecimo ad edictum: Idem Pomponius ait in pretio emptionis et venditionis naturaliter licere contrahentibus se circumvenire. Ello significa, que el mismo Pomponio dice, que en el precio de la compra y de la venta es naturalmente lícito a los contratantes engañarse. Y asimismo Ulpiano citando a este jurista reafirma el principio de la validez de los negocios jurídicos libremente acordados entre las partes.

D.19,2,22,3 Paulus libro trigesimo quarto ad edictum: Quemadmodum in emendo et vendendo naturaliter concessum est quod pluris sit minoris emere, quod minoris sit pluris vendere et ita invicem se circumscribere, ita in locationibus quoque et conductionibus iuris est. Con lo cual así como en el comprar y vender está naturalmente permitido comprar por menos lo que valga más, y vender por más lo que valga menos, y de este modo engañarse mutuamente, así también es de derecho en las locaciones y conducciones. En este sentido opina Paulo, extendiendo el principio de la autonomía de la voluntad a otros contratos. D.19,2,23 Hermogenianus libro secundo iuris epitomarum: Et ideo praetextu minoris pensionis, locatione facta, si nullus dolus adversarii probari possit, rescindi locatio non potest. Significa que no puede rescindirse la locación bajo pretexto de haberse hecho la locación por menos renta, si no pudiera probarse dolo alguno del adversario.

${ }^{50}$ FERNÁNDEZ DE BUJÁN, F., Sistema contractual romano, Madrid 2003, 183-184; ROCA TRÍAS, M. ${ }^{a}$ E., Problemas de l'engany de mitges, en Revista Jurídica de Cataluña, 2 (1967), 266; vid. GONZÁLEZ FERNÁNDEZ, R., Las estructuras ideológicas del Código de Justiniano, cit., 45-46, sobre la investigación llevada a cabo para determinar los criterios que rigen el establecimiento de las interpolaciones en el Corpus Iuris Civilis, destaca el criterio histórico positivo en el que se establece la interpolación en virtud de su identificación con principios fijados por el derecho nuevo o de su correspondencia con las reformas introducidas por Justiniano o sus comisarios; y el criterio negativo de que existen las interpolaciones consistente en la incompatibilidad del principio enunciado por el jurisconsulto con la situación del derecho clásico en general, o con el estado del derecho en la época del jurisconsulto, o más limitadamente con las opiniones de aquel jurista; DEKKERS, R., La lésion énorme. Introduction a l'histoire des sources du droit, cit., 19; ZIMMERMANN, R., The law of 
venta, otorgándose al comprador la opción ya concedida: «...electione iam emtori praestita servanda» ${ }^{51}$, con lo cual, con estas últimas palabras la consulta se resuelve mediante otra remisión a otra consulta evacuada en el rescripto CI.4,44,2 años antes ${ }^{52}$. Afirma Gradenwitz ${ }^{53}$ que todo el párrafo final «nisi minus dimidia iusti pretii, quod fuerat tempore venditionis, datum est, electione iam emptori praestita servanda» lo considera interpolado, argumentando que Diocleciano no podría referirse en el año 293 a un rescripto del año 285. Una posición contraria vemos en Landucci ${ }^{54}$ quien defiende la posibilidad de que los emperadores Diocleciano y Maximiano pudieron confirmar ocho años después lo que decidieron en un rescripto de ocho años antes.

Podemos decir que el contexto de esta última frase se debe interpretar a la luz de la Ley Segunda, pues al final del CI.4,44,8 no se indica la solución, por lo que obligaría al comprador del año 293 a descubrirla en el rescripto CI.4,44,2 del año 285, en el sentido de que se concede al comprador la facultad de elegir entre la rescisión del contrato, mediante la autoridad judicial, o el complemento del justo precio. Por lo que en opinión de García Vallés, todo ello hace pensar

obligations, cit., 259-260; ALBERRUCHE DÍAZ-FLORES, M. ${ }^{\text {a }}$ M., La rescisión por lesión en el derecho civil español, cit., 38; ALBERTARIO, E., Studi di Diritto Romano, V, Milano, 1937, 610 n 1.

${ }^{51}$ DEKKERS, R., La lésion énorme. Introduction a l'histoire des sources du droit, cit. 22 .

${ }^{52}$ ARANGIO RUIZ, V., La compravendita in Diritto Romano, cit., 147, sobre esta remisión de un rescripto a otro para evacuar una consulta, dice: «Ma il rinvio del rescritto del 293 ad una facoltà contemplata in altro del 285 era possibile soltanto quando l'uno e l'altro avevano cessato di essere rescritti, cioè risposte fornite dal principe ai pivati che gli sottoponevano un punto di diritto, per divenire capitoli o articoli di una compilazione legislativa»; DEKKERS, R., La lésión énorme. Introduction a l'histoire des sources du droit, cit., 22; SIRKS, A. J. B., La «laesio enormis» en Droit Romain et Byzantin, en Revue d'Histoire du droit, cit., 295; FÉLIX CHAMIE, J., Rescisión por lesión enorme: el problema del origen, cit., 31, dice que Hermogeniano conectaría la decisión del año 293 con la del sño 285, y agrega el quod fuerat tempore; este mismo autor en FÉLIX CHAMIE, J., Rescisión por lesión enorme: el problema del origen, cit. 31 n.116, añade que «Hermogeniano realizaría una interpretación del rescripto del 285 armonizando la esfera de principios existentes en el derecho privado, esto es, el naturaliter invicem circumvenire con la lesión ultra dimidium a la luz del humanum est».

${ }^{53}$ GRADENWITZ, O, Interpolazioni e interpretazioni, cit., 14; FÉLIX CHAMIE, J., Rescisión por lesión enorme: el problema del origen, en Revista de Derecho Privado, cit., 31; KLAMI H. T., "Laesio enormis» in Roman Law, cit., 55; SIRKS, A. J. B., La «laesio enormis» en Droit Romain et Byzantin, en Revue d'Histoire du droit, cit., 296; MARTÍN-CASALS, M., Lesió "ultra dimidium» i equivalencia: naturalesa de la lesió $i$ àmbit d'aplicació/tesi doctoral, Barcelona 1984, cit., 33; HACKL, K., Zu den Wurzlen der Anfechtung wegen "laesio enormis», cit., 154.

${ }^{54}$ LANDUCCI, L, La lesione enorme nella compra e vendita, cit., 1195; HACKL, K., Zu den Wurzlen der Anfechtung wegen «laesio enormis», en ZSS 98 (1981) 148.

(C) UNED. Revista de Derecho UNED, núm. 18, 2016 
que el rescripto sería retocado por Justiniano y por compiladores posteriores ${ }^{55}$. Cabe decir que durante la época de Diocleciano como en la de Justiniano, aunque las prestaciones fuesen distintas y hubiese lesión para una de las partes no se hacía nulo el contrato, sino que se daba la posibilidad de anularlo a quien la pidiese, por un principio de justicia conmutativa, complementando el precio hasta llegar al justo, sin que hubiese necesidad de rescindir la venta ${ }^{56}$. Así pues según opinión de Solazzi ${ }^{57}$ la rescisión de la venta por lesión enorme fue ordenada por Justiniano, y los rescriptos de Diocleciano CI.4,44,2 y CI.4,44,8 fueron interpolados, dado que esta institución no fue incluida en el Código Teodosiano ni en ninguna de las constituciones posteriores a Diocleciano.

Leicht ${ }^{58}$ considera que los motivos que indujeron a Justiniano a interpolar los rescriptos citados fueron los abusos producidos sobre la pequeña y mediana propiedad inmobiliaria, por los codiciosos especuladores que, aprovechándose de la carestía de la época, compraban muchos inmuebles a precios irrisorios, explotando a los empobrecidos propietarios ${ }^{59}$. Asimismo las variaciones monetarias hacían

${ }^{55}$ Vid. GARCÍA VALLÉS, R., cit.,19; SOLAZZI, S., L'origine storica della rescissione per lesione enorme, cit., 53.

${ }^{56}$ ROCA TRÍAS, M. ${ }^{a}$ E., Problemas de l'engany de mitges, en Revista Jurídica de Cataluña, cit., 267.

${ }^{57}$ SOLAZZI, S., L'origine storica della rescissione per lesione enorme, cit., 68 y ss; RASCÓN GARCÍA, C., Sobre la recepción de la "laesio ultra dimidium» como causa de rescisión de los contratos en el derecho español, cit., 140; JOLOWICZ, H. F., The origin of «laesio enormis», cit., 70; VOLTERRA, E., Diritto Romano e Diritto Orientali, cit., 254-255; VOLTERRA, E., Istituzioni di Diritto Privato Romano, cit., 501; sobre las interpolaciones justinianeas de los rescriptos en cuestión, comparte la misma opinión WESTBROOK, R., The Origin of «Laesio Enormis», en RIDA LV (2008)41; también vid. SANFILIPPO, C., "Istituzioni di Diritto Romano, Messina 1996, 341; GARCÍA SÁNCHEZ, J., La "laesio enormis» y el precio de la subasta, en Actas del II Congreso Iberoamericano de Derecho Romano, cit., 79; GÓMEZ CAMACHO, F. \& ROBLEDO, R, Salamanca 1998, 68; GARCÍA GARRIDO, J. M., Derecho Romano Privado, Madrid 1988, 632; GUZMAN BRITO, A., Derecho Privado Romano, II, Santiago - Chile, 1996, 137; MIRABELLI, G., La rescissione del contratto, Napoli 1962, 3-7.

${ }^{58}$ LEICHT, P. S., "Laesio enormis e Justum pretium», cit., 40-41.

${ }^{59} \mathrm{Vid}$. STANOJEVIC, O., "Laesio enormis» e contadini tardoromani, cit., 500, este autor hace mención a los principios conservadores y antifeudales que a menudo inspiraron las leyes de los emperadores romanos durante la legislación postclásica, y que no estaban basados en la necesidad de defender a los pobres, sino en contrarrestar a los potentiores, que se habían convertido en el núcleo de un nuevo sistema social y económico; GAGÉ, J., Les classes sociales dans l'Empire Romain, Paris 1971, 401; ÁLVAREZ VIGARAY, R. \& AYMERICH DE RENTERÍA, R.,, La rescisión por lesión en el derecho civil español común y foral, cit., 19, que hablan sobre el origen de la rescisión por lesión ante la necesidad de poner límite a los abusos de las personas que se aprovechaban de la venta de bienes de los pequeños propietarios, motivada por la grave crisis económica que atravesaba el Bajo Imperio, por un precio inferior al real; 
más penosa esta situación, por lo que Justiniano, con la transformación de los rescriptos CI.4,44,2 y CI.4,44,8, crearía un remedio para los pequeños propietarios que les permitiría obtener la rescisión de la venta hecha a un precio vil ${ }^{60}$, mediante la autoridad de un juez ${ }^{61}$.

\section{LA TEORÍA DE LA AUTENTICIDAD: DIOCLECIANO Y EL ORIGEN DE LOS RESCRIPTOS}

Frente al carácter interpolacionista de las teorías mencionadas con anterioridad, pasamos a analizar los autores que defienden la originalidad de los rescriptos CI.4,44,2 y CI.4,44,8. Entre estos autores destaca Stanojevic ${ }^{62}$ quien afirma que para el derecho clásico no era extraña la idea de la rescisión del contrato por la desproporción de las prestaciones. En el inicio del siglo III d. C. se encontraba la posibilidad de rescindir el contrato, no como principio general, sino como circunstancia particular, ante la existencia de un grande damnum tal como viene reflejado en el texto D.4,4,9pr. ${ }^{63}$ o en otro caso de

SIRKS, B, «Laesio enormis» again, en RIDA, LIV, cit., 466; vid. DE MARTINO, F., Historia económica de la Roma Antigua, II, Madrid 1985, 502-503, hace también alusión a la formación de la propiedad latifundista y a la concentración de la propiedad que se vio favorecida por los intereses de la res privata imperial, de las clases elevadas y de la Iglesia. Los grandes propietarios presionaban a los pequeños propietarios para adquirir sus tierras; el endeudamiento y los intereses favorecían las ventas; MIRABELLI, G., La rescissione del contratto, cit., 6.

${ }^{60} \mathrm{DE}$ MEDIO, Il patto di non prestare l'evizione e il dolo del venditore nel diritto romano classico, en BIDR 16 (1904) 66, hace alusión a los preceptos éticos introducidos por Justiniano que influyeron en el instituto de la rescisión por lesión enorme, pues el valor y el precio de la cosa debe ser proporcional, ya que el ideal ético exige que el comprador, convencido de haber comprado a un buen precio, debe restituir voluntariamente la diferencia, y viceversa, para el vendedor que ha obtenido más del valor del objeto de la compraventa; también en CICERÓN, Los Oficios, libro III, capítulo XV, Leyes de los romanos contra el dolo malo y el fraude, en Obras completas de Marco Tulio Cicerón, T. IV, trad. Valbunena M., 179, observamos también como precepto ético, que ni el dolo ni el fraude deben de utilizarse por ambas partes contratantes en el negocio de compraventa, tras exponer que: «El dolo malo consiste, según dice Aquilio, en el fingimiento y simulación. Este supuesto, se ha de desterrar de cualquier contrato toda mentira; de manera que ni el vendedor use de fraude con el comprador, ni tampoco éste contra aquél que algo le vendiere; y si se avocaren las dos partes, basta una sola palabra del uno y del otro.»; ALBERTARIO, E., Studi di Diritto Romano, V, Milano, 1987, 422.

${ }^{61}$ Cfr. LEICHT, P. S., "Laesio enormis e Justum pretium», cit., 41; MONTAÑANA CASANÍ, A., La rescisión por lesión (origen, evolución histórica y recepción en Derecho moderno), cit., 59-60.

${ }^{62} \mathrm{Vid}$. STANOJEVIC, O., "Laesio enormis» e contadini tardoromani, en Academia Romanistica Constantiniana, cit. 222-223.

${ }^{63}$ D.4,4,9pr. Ulpianus 11 ad ed. Si ex causa iudicati pignora minoris capta sint et distracta, mox restitutus sit adversus sententiam praesidis vel procuratoris Caesaris, 
enorme damnum en CI.2,28, $1^{64}$, cuya idea inspiradora era la misma que la de la laesio enormis. En opinión de este mismo autor una ley como ésta que abandona la tradición clásica, corresponde más bien a Diocleciano, reformador por excelencia, y no a Justiniano que más bien era un tradicionalista. La idea que sirvió de base a la laesio enormis era idéntica a la que inspiró el Edictum de pretiis rerum venalium, y por lo tanto fue Diocleciano quien dio origen a esta institución.

Asimismo, Leicht ${ }^{65}$ destaca la teoría de Dickstein basada en que la doctrina de la lesión surgió en la ley judía y se desarrolló por el rabino Yohanan perteneciente a la Academia de Tiberíades, donde enseñó durante los años 279-280 d. C., y que luego penetró en la escuela de derecho de la Cesárea romana, y allí se difundió al mundo romano de Diocleciano $^{66}$.

Durante la época clásica avanzada la rescindibilidad de un contrato por lesión ultra dimidium todavía era desconocida, pero se empezaba a sentir la exigencia, en casos excepcionales o por razón de justicia y equidad, de romper con la regla vigente en materia de libertad contractual, en donde las partes podrían sufrir limitaciones justificadas con la necesidad de evitar excesivos desequilibrios patrimoniales

videndum, an ea revocari debeant, quae distracta sunt: nam illud certum est pecuniam ex causa iudicati solutam ei restituendam. sed interest ipsius corpora potius habere: et puto interdum permittendum, id est si grande damnum sit minoris. El texto trata de la venta de prendas de un menor y la posibilidad de obtener su restitución contra la sentencia del pretor o del procurador del César; la respuesta que se da consiste en afirmar la restitución del dinero pagado por causa de lo juzgado, o bien se ha de permitir restituir al menor en las mismas cosas que se vendieron, si bien le interesa tener preferentemente las mismas cosas, si fuere grande su perjuicio, por lo que el elemento relevante que provoca la revocación de la venta, más que la minoría de edad del sujeto, consistirá en el gran daño que va a sufrir; SCIUTO, P., Sulla C. D. Rescissione per Lesione Enorme, cit., 415-416.

${ }^{64}$ CI.2.28.1: Imperatores Diocletianus, Maximianus Etiam adversus venditiones pignorum, quae a creditoribus funt, minoribus subveniri, si tamen magno detrimento adficiantur, iam pridem placuit. si igitur pignori captis praediis ac distractis enorme damnum ex huiusmodi venditione passos vos ostenderitis, praesertim cum hodieque vos minores esse adfirmetis, auxilium restitutionis vobis impertietur. "Diocl. et Maxim. aa. Sabinae et Aliis. * 'a 290 d. $x \mathrm{k}$. dec. sirmi ipsis iiii et iii aa. conss.'. En este texto se concede a los menores de edad el auxilio de la restitución contra las ventas de prendas que se hacen por los acreedores y que les causen gran perjuicio, y también cuando se tomen en prenda y vendan unos predios resulte un enorme perjuicio, por lo que el motivo de revocar la venta no solamente dependerá de la minoría de edad sino también de la entidad del daño sufrido; SOLAZZI, S., L'origine storica della rescissione per lesione enorme, cit., 62; SCIUTO, P., Sulla C. D. Rescissione per Lesione Enorme, cit., 414.

${ }^{65}$ LEICHT, P. S., "Laesio enormis e Justum pretium», cit., 43.

${ }^{66}$ Opuestamente, JOLOWICZ, H. F., The origin of «laesio enormis», cit., 57, se pronuncia en el sentido de que Diocleciano se opondría a la introducción de elementos extranjeros en las leyes, lo cual podría evidenciar que las leyes judias no influirían en el origen de la rescisión por lesión. 
entre ambas, sobre todo cuando una de las mismas fuese jurídicamente más débil, como en el caso de un menor ${ }^{67}$.

Por lo que respecta a la originalidad del rescripto CI.4,44,2, defensores como Landucci destacan que en la frase tu vel pater tuus (tú o tu padre), el sujeto no concuerda con el verbo distraxerit ${ }^{68}$, y sostiene que esta forma sintáctica era frecuente en los textos en latín, descartando cualquier tipo de interpolación ${ }^{69}$.

Asimismo en el citado rescripto intervinieron varios compradores emptoribus fundum venditum, y que cuando se ofreció la opción de elegir entre pagar la diferencia del precio o devolver la cosa al vendedor, se hizo referencia a un solo comprador si emptor elegerit, ya que con uno solo era suficiente para pagar la diferencia entre el precio justo y el precio de compra, por lo que en opinión de Klami estas observaciones son infundadas para negar la autenticidad sustancial del rescripto ${ }^{70}$. El estudio lingüístico y sistemático realizado sobre el texto de la lex secunda es poco convincente para negar su autenticidad, pues para determinar una interpolación hay que basarse tanto en razones formales como sustanciales. Si se supone que la causa del origen de la laesio enormis fueron los problemas socioeconómicos, se debería aceptar al emperador Diocleciano como el autor de la adaptación del contrato de compraventa a la doctrina de la laesio enormis, pues Justiniano no llegaría a enfrentarse con unos problemas socioeconómicos de tan importante magnitud. Asimismo fue el malestar social como argumento socio-estructural el motivo que dio lugar al decreto de precios en relación con la doctrina de la laesio enormis, y no por motivos ideológicos como los que asume Justiniano como emperador cristiano, y que son proclives a los modelos de equidad ${ }^{71}$.

Sobre el rescripto CI.4,44,8 Landucci ${ }^{72}$ descarta su interpolación al afirmar que está compuesta de dos partes, la primera comprende desde el inicio hasta la palabra invalidum est, y la segunda desde quod

${ }^{67}$ SCIUTO, P., Sulla C. D. Rescissione per Lesione Enorme, cit., 419.

${ }^{68}$ Vid. DEKKERS, R., La lésion énorme. Introduction a l'histoire des sources du droit, cit., 24; ZIMMERMANN, R., The law of obligations, cit., 260; SOLAZZI, S., L'origine storica della rescissione per lesione enorme, cit., 53; MONTAÑANA CASANÍ, A., La rescisión por lesión (origen, evolución histórica y recepción en Derecho moderno), cit., 47.

${ }^{69}$ Vid., LANDUCCI, L., La lesione enorme nella compra e vendita, en Atti del R. Istituto Veneto di Scienze, Lettere ed Arti, LXXV (1916) 1194-1995.

${ }^{70}$ Vid. KLAMI H. T., "Laesio enormis» in Roman Law, cit., 55; HACKL, K., Zu den Wurzlen der Anfechtung wegen "laesio enormis», cit., 152 y ss.

${ }^{71}$ KLAMI H. T., "Laesio enormis» in Roman Law, cit., 51; SCIUTO, P., Sulla C. D. Rescissione per Lesione Enorme, cit., 411.

${ }^{72}$ Vid. LANDUCCI, L., La lesione enorme nella compra e vendita, cit., 1195-1196. 
hasta el final, en donde no existe contradicción alguna entre las mismas, sino una concordancia lógica, ya que el paulo minori de la primera parte está condicionado al nisi minus dimidia parte de la segunda parte, pues no se puede pretender la rescisión de un contrato de compraventa con un precio poco menor que el verdadero, a no ser que la diferencia sea menos de la mitad, ya que entonces el precio no es poco menor sino mucho menor, por lo que en este caso cabria la concesión de la rescisión por lesión.

Así pues, los rescriptos de Diocleciano CI.4,44,2 y CI.4,44,8 no fueron interpolados, fueron aceptados sin modificaciones de ningún tipo en la Compilación Justinianea, ya que el instituto rescisorio no fue aplicado por los emperadores sucesivos a Diocleciano porque su práctica era contraria al principio de la libertad contractual y, asimismo, la idea del precio justo se debe a Diocleciano ${ }^{73}$.

Maynz $^{74}$ es otro de los autores que considera que la rescisión por laesio ultra dimidium era una creación del emperador Diocleciano, y que el motivo excepcional de su aparición se debe a la suposición de que el vendedor no hubiera vendido la cosa a un precio tan mínimo, si no se hubiese visto forzado por la necesidad, y por tal motivo el legislador no quiso que el comprador se aprovechase de esta situación.

\section{TEORÍAS INTERMEDIAS SOBRE EL ORIGEN E INTERPOLACIÓN DE LOS RESCRIPTOS: LOS COMPILADORES JUSTINIANEOS}

Pasamos ahora a la postura intermedia sobre el origen e interpolación de los rescriptos CI.4,44,2 y CI.4,44,2, adoptada por distintos autores, empezando con la teoría de $\mathrm{Nicolau}^{75}$, que dice que los compiladores justinianeos tras revisar el texto de CI.4,44,2, este rescripto

${ }^{73}$ LANDUCCI, La lesione enorme nella compra e vendita, en Atti del R. Istituto Veneto di Scienze, Lettere ed Arti, LXXXV (1916) 1194 y ss.; PICIRILLO, A., S.v. «Rescissione», cit., 577; MARGADANT, G. F., La historia de la»laesio enormis»como fuente de sugerencias para la legislación moderna, en Boletín Mexicano de derecho comparad, cit. 36; ÁLVAREZ VIGARAY, R. \& AYMERICH DE RENTERÍA,, R., cit., 18-19; VISKY, K., Appunti sulla origine Della lesione enorme, cit., 45-46; GUTIÉRREZ ALVIZ, "Laesio enormis», en Boletín de la Universidad de Granada, cit. 384; SCIUTO, P., Sulla C. D. Rescissione per Lesione Enorme, cit., 408.

${ }^{74}$ MAYNZ, C., Curso de Derecho Romano, cit., 252; GUTIÉRREZ ALVIZ, "Laesio enormis», en Boletín de la Universidad de Granada, cit., 387; PETIT, E., Tratado elemental de Derecho Romano, Madrid 1924, cit., 391.

${ }^{75}$ Vid. NICOLAU, M., Les origines de la «laesio enormis», en Revue Historique de Droit Français et Étranger, 15 (1936) 207-208. 
no tendría en su origen el mismo alcance que tuvo en el derecho de Justiniano, y admite la posibilidad de haberse podido determinar cual fue su contenido primitivo. Sobre el empleo de la palabra distraxit que aparece en el citado rescripto parece indicar que se trataba de una distractio bonorum ${ }^{76}$. Este mismo autor distingue dos tipos de venta, una venta voluntaria en la que Diocleciano no autorizaría la rescisión por causa de lesión, y otra venta en materia fiscal en la que se admitiría la rescisión cuando el precio de la adjudicación fuese inferior a la estimación hecha por los agentes del fisco ${ }^{77}$. También afirma que la rescisión de ventas fiscales por causa de lesión existiría antes de Diocleciano, y que el plazo para interponer esta acción de

${ }^{76}$ GARCÍA GARRIDO, M. J., S.v.. "La distractio bonorum», Diccionario de Jurisprudencia Romana, cit., 105. La distractio bonorum consistía en la venta de los bienes por partes, destinada al pago de los acreedores en evitación de los perjuicios de una venta del patrimonio total. Esta clase de venta comenzó a admitirse en algunos casos como el del pupilo que no tiene tutor y es heredero del ejecutado, o en el caso del furiosus o el pródigo. A estas personas se les nombraba un curator bonorum para la administración y venta separada de bienes. Posteriormente, un senadoconsulto de comienzos del Principado y de fecha incierta, extendió en forma de ejecución a las llamadas personas de rango senatorial. El procedimiento ejecutivo de la distractio bonorum evitaba la missio in bona y la nota de infamia.

${ }^{77}$ Sobre la rescisión de ventas fiscales por causa de lesión se hace alusión en un texto de Calístrato D.49,14,3,5: Callistratus 3 d. $i$. Fisci. Divi fratres rescripserunt in venditionibus fiscalibus fidem et diligentiam a procuratore exigendam et iusta pretia non ex praeterita emptione, sed ex praesenti aestimatione constitui: sicut enim diligenti cultura pretia praediorum ampliantur, ita, si neglegentius habita sint, minui ea necesse est.; también en Cth.10,17,3: Imppp. Valentinianus, Theodosius et Arcadius aaa. ad Magnillum vicarium Africae. Si quos debitorum mole depressos necessitas publicae rationis adstringat proprias distrahere facultates, rei qualitas et redituum quantitas aestimetur, ne, sub nomine subhastationis publicae locus fraudibus relinquatur et, possessionibus viliore distractis, plus exactor ex gratia quam debitor ex pretio consequatur. Hi postremo, sub empti* titulo, perpetuo dominii iure potiantur, qui tantum annumeraverint fisco, quantum exegerit utilitas privatorum. Etenim periniquum est, $u t$, alienis bonis sub gratiosa auctione distractis, parum accedat publico nomini, quum totum pereat debitori. Dat. XIII. kal. iul. Aquileia, acc. id. ian. Hadrumeti, post cons. Tatiani et Symmachi vv. cc. Interpretatio. Si quicumque* publici debiti enormitate constringitur, ut non possit hoc ipsum debitum nisi vendita propria facultate dissolvere, in eius modi debito hanc exactores formam servare debebunt, ut non ita rem praecipitent, ut res minore, quam valeat, pretio distrahatur, nec tales sub quolibet coIludio provideant emptores*, ut et debitor proprietatem perdat, et parum fiscus acquirat.; y por último en CI.10,1,3: Imperator Gordianus Si minori pretio, quam res est, aperta fraude emptoris vel gratia quae obligata sunt a fisco venierunt, aditus procurator meus debitam quantitatem inferenti restitui ea praedia iubebit. y en CI.10,3,2: Imperator Gordianus Duplex ratio desiderium tuum iuvat, et quod praetermissa hastarum sollemnitate possessiones tuas ex officio distractas suggeris, et quod pretii vilitate ob exiguum debitum gratiosam emptionem in fraudem tuam utilitatemque rationum mearum adversarium commentum fuisse dicis. quapropter illicita ista redargue, tam indemnitati fisci consulturus quam tuae securitati opem laturus; CARRELLI, C., C.2,36,1 e 3 e l'origine della rescissione per "laesio enormis...», en SDHI, 3 (1937), 447-448. 
rescisión sería el mismo de cuatro años que el que se venía aplicando en material fiscal ${ }^{78}$. Meynial ${ }^{79}$ considera que si bien atribuye al emperador Diocleciano la introducción de la rescisión de la venta por lesión de más de la mitad en el rescripto CI.4,44,2, la crítica moderna se inclina en pensar que la rescisión por lesión sería rechazada en el Código Teodosiano y que, Justiniano, debería alterar el texto ${ }^{80}$, ya que en el siglo IV d. C. la práctica romana se esforzaba en proteger a la parte contratante que fuese víctima de una grave lesión ${ }^{81}$. Y Mon$n_{i e r}{ }^{82}$ es de la opinión que, la decisión tomada por Diocleciano de defender a la parte débil del contrato frente a los poderosos, dio origen a la rescisión por lesión de la venta ${ }^{83}$; no obstante esta decisión le parece demasiado particular y lejos del derecho común, por lo que sería motivo para los emperadores posteriores dejarla de lado, y asimismo en el Código Teodosiano el minus pretium no era una causa de rescisión de la venta ${ }^{84}$. No obstante, el aumento de los abusos en las ventas por las clases poderosas, daría lugar a que los compiladores del Código de Justiniano insertasen en la compilación el instituto de la rescisión por lesión ${ }^{85}$.

${ }^{78}$ NICOLAU, M., Les origines de la «laesio enormis», en Revue Historique de Droit Français et Étranger, 15 (1936) 208; GUTIÉRREZ ALVIZ, "Laesio enormis», en Boletín de la Universidad de Granada, cit., 385.

${ }^{79}$ MEYNIAL, Des condition requises au Moyen-Age pour l'application de la rescision de la vente pour lesión d'outre-moitié, en Mélanges P. F. Girard: études de droit romain dédiées a M. P. F. Girard, Paris 1912, 201.

${ }^{80}$ FERRINI, C., Manuale di Pandette, Milano, 1908, 681 n 2.

${ }^{81}$ SOLAZZI, S., L'origine storica della rescissione per lesione enorme, cit., 68-69; en esta misma línea CORNIL, G., Droit Romain: aperçu historique sommaire ad usum Cupidae Legum Iuventutis, Bruxelles 1921,630, considera como medida de defensa aplicable a las ventas contra la avidez de los especuladores, y que el Código de Justiniano establece mediante dos constituciones de Diocleciano, CI.4,44,2 y CI.4,44,8, probablemente interpoladas, que se atribuya al vendedor del inmueble, lesionado en más de la mitad del precio, el derecho de rescindir la venta, mientras que el comprador tiene la facultad de conservar el inmueble completando el precio.

${ }^{82}$ MONNIER, H., La lesion de plus de moitié dans la vente, en Études de drot byzantin, en NRHD 24 (1900) 182; igualmente CARRELLI, C., C.2,36,1 e 3 e l'origine della rescissione per "laesio enormis...», cit., 446-450, pone en duda la clasicidad del texto primitivo y su posterior interpolación en la compilación justinianea.

${ }^{83}$ Opinión también compartida por COLLINET-GIFFARD, Droit Romain, Précis de droit romain. Vol. II, París 1929, 48, como medida atribuida por Diocleciano en la constitución CI,4,44,2 que se contiene en el Código de Justiniano, pero bajo la deuda de que el texto fuera objeto de interpolación o consecuencia de un error.

${ }^{84}$ HUVELIN, Cours élémentaire de droit romain, vol. II (1929) 138, este autor admite la posibilidad de que las constitutiones atribuidas a Diocleciano CI.4,44,2 y CI.4,44,8, fueron profundamente interpoladas por Justiniano, ya que constituciones imperiales posteriores, que fueron acogidas en el Código Teodosiano y en la Lex Romana Visigothorum, afirman que el contrato de venta no se rescinde por una simple cuestión de precio, a no ser que existiera dolo o violencia de una de las partes contratantes.

${ }^{85}$ En este sentido, ALBERTARIO, E., Studi di Diritto Romano, cit., 174 n 2. 
Intermedia podría decirse la postura de TAPANI KLAMI ${ }^{86}$ y de Boudenwijn SIRKS ${ }^{87}$, quienes cuestionarían la existencia de la regla dioclecianea sobre la rescisión de la venta por causa de lesión enorme, y serían Justiniano y sus compiladores quienes darían el primer paso hacia el ajuste de los contratos inequitativos a través de esta institución.

\section{CONCLUSIONES}

De todo lo expuesto se puede concluir que de las investigaciones llevadas a cabo sobre las interpolaciones de los textos CI.4,44,2 y CI.4,44,8 existen tres grupos de opiniones. En primer lugar participan aquellos autores que piensan que la rescisión por lesión ultradimidium sería una introducción de los compiladores de Justiniano, mediante la interpolación de los rescriptos CI.4,44,2 y CI.4,44,8, dado que las incorrecciones gramaticales, la falta de coordinación sintáctica y su difícil armonización con otros textos del Corpus Iuris Civilis y del Codex Theodosianus podrían demostrar la interpolación de ambos textos.

El fundamento ético y religioso de la rescisión por lesión estaría conectado con la doctrina cristiana, que no llegaría a desarrollarse hasta la época de Justiniano, con lo cual tampoco se correspondería con la etapa de Diocleciano, pues se supone que el texto CI.4,44,2, con la célebre frase humanum est, llegaría a estar interpolado.

Asimismo la teoría del iustum pretium unida a esta institución y que aparece recogida en CI.4,44,2 con las palabras iusto pretio, no se correspondería con la época de Diocleciano, sino que tendría un reconocimiento general en el derecho justinianeo, por lo que el texto habría sido interpolado por los compiladores de Justiniano.

Tampoco se cree que Diocleciano estableciera este instituto rescisorio como regla general, ya que este emperador en CI.4,44,2 resolvió un caso concreto, e introducirlo como norma general supondría alterar la estructura clásica del contrato de compraventa basada en la autonomía de la voluntad contractual.

Otro sector de la doctrina romanista defiende que la rescisión por lesión ultra dimidium debe su origen a Diocleciano y desde entonces se mantendría en vigor, descartando cualquier tipo de interpolación en los

${ }^{86}$ KLAMI H. T., «Laesio enormis» in Roman Law, cit., 63.

${ }^{87}$ SIRKS, B., Quelque remarques sur la possibilité d'une règle dioclétienne sur la rescission d'une vente à cause de lésion énorme (laesio enormis), en ATTI dell'Accademia romanistica constantiniana V, Perugia, 1983, 47. 
textos CI.4,44,2 y CI.4,44,8. Asimismo, para el derecho clásico no era extraña la idea de la rescisión del contrato por la desproporción de las prestaciones, pues ya en el inicio del siglo III d. C. cabía la posibilidad de rescindir el contrato, no como principio general, sino como circunstancia particular, ante la existencia de un grande damnum o de un enorme damnum cuya idea inspiradora era la misma que la de la laesio enormis. Por lo tanto una ley que abandonase aquella tradición clásica, correspondería a Diocleciano, que fue un reformador por excelencia.

No obstante, la grave situación económica y social que atravesaba el Bajo Imperio durante el siglo III d. C., y la protección de los pequeños propietarios de fundos, oprimidos y explotados por los grandes propietarios, sería motivo para que Diocleciano introdujera esta institución.

Por último, destaca la postura intermedia de aquellos autores que opinan que si bien la rescisión por lesión ultra dimidium tuvo su origen con Diocleciano, admiten la posibilidad de que los textos recogidos en CI.4,44,2 y CI.4,44,8 fueron revisados por los compiladores justinianeos, por lo que no tendrían en su origen el mismo alcance que en el derecho de Justiniano.

Las decisiones adoptadas por Diocleciano para la creación de ambos rescriptos, impulsadas por las condiciones socio-económicas de su época, no serían compartidas por los emperadores posteriores, por lo que dichos textos no serían incluidos en el Código Teodosiano, si bien después Justiniano, a causa de una grave crisis económica, daría vigencia a esta institución.

\section{BIBLIOGRAFÍA}

ALBERRUCHE DÍAZ-FLORES, M. ${ }^{\mathrm{a}}$ M., La rescisión por lesión en el derecho civil español, Madrid 2010.

ALBERTARIO, Iustum pretium et iusta aestimatio, en BIDR, 1921.

ALBERTARIO E., Studi di Diritto Romano, v. III, Milano, 1936.

- Studi di Diritto Romano, V, Milano, 1937.

- Studi di Diritto Romano, V, Milano, 1987.

ÁLVAREZ VIGARAY, R. y DE AYMERICH DE RENTERIA, R., La rescisión por lesión en el derecho civil español común y foral, Granada 1989.

ANTEQUERA, J. M. ${ }^{\text {a }}$, Historia de la legislación romana desde los tiempos más remotos hasta nuestros días, Madrid 1874. 
ARANGIO RUIZ, V., Historia del Derecho Romano, Madrid 1974.

BENEDETTINI, E., Rescissione della vendita per causa di lesione en Archivio giurídico «Filippo Serafini», 84 (1910).

BONFANTE, P., La data della lesione enorme, en Rivista del diritto comérciale e del diritto generale delle obbligazioni, 1921.

BONINI, ROBERTO., Introduzione allo Studio dell'età giustinianea, Bologna 1989.

BRASLOFF, S., Zur Lehre von der laesio enormis in byzantinischen Recht en Zeitschrift für leichende Rechtswissenschaft 27 (1912).

CARRELLI, C., C.2,36, 1 e 3 e l'origine della rescissione per «laesio enormis...», en SDHI, 3 (1937).

COLLINET-GIFFARD, Droit Romain, Précis de droit romain, vol. II, París 1929.

CORNIL, G., Droit Romain: aperçu historique sommaire ad usum Cupidae Legum Iuventutis, Bruxelles 1921.

DEKKERS, R., La lésion énorme. Introduction a l'histoire des sources du droit, Paris 1937.

DE MARTINO, F., Historia económica de la Roma Antigua, II, Madrid 1985.

DE MEDIO, Il patto di non prestare l'evizione e il dolo del venditore nel diritto romano classico, en BIDR 16 (1904) 66.

DÍAZ, E., Instituciones de Derecho Romano, II, Barcelona 1929.

FÉLIX CHAMIE, J., Rescisión por lesión enorme: el problema del origen, en Revista de Derecho Privado, 19 (2010).

FERNÁNDEZ DE BUJÁN, F., Sistema contractual romano, Madrid 2003.

FERRINI, C., Manuale di Pandette, Milano, 1908.

GAGÉ, J., Les classes sociales dans l'Empire Romain, Paris 1971.

GARCÍA GARRIDO, J. M., Derecho Romano Privado, Madrid 1988.

GARCÍA GARRIDO, M. J., S.v.. «La distractio bonorum», Diccionario de Jurisprudencia Romana, 2000.

GARCÍA GARCÍA, A. y ALONSO RODRÍGUEZ, B., El pensamiento económico y e mundo del derecho hasta el siglo XVI, en El pensamiento económico en la escuela de Salamanca, Salamanca 1998. 
GARCÍA SÁNCHEZ, J., La «laesio enormis» y el precio de la subasta, en Actas del II Congreso Iberoamericano de Derecho Romano, Oviedo 1998.

GARCÍA SÁNCHEZ, J. y GARCÍA FUEYO, B., «Naturaliter circumvenire de pretio». La doctrina jurídica salmantina del siglo XVI, en IX Congreso Internacional XII Iberoameriacano de Derecho Romano, I, Las Palmas de Gran Canaria 2007.

GARCIA VALLES, R., Rescisión por «laesio ultradimidium», Barcelona, 1962.

GHIRARDI, J. C., La «Laesio Ultradimidium», en XIV Congreso Latinoamericano de Derecho Romano, Buenos Aires 2004.

GHIRARDI, J. C. y FILIPPI DE GHIRARDI, M. C., La «laesio ultradimidium», en Revista General de Derecho Romano, ISSN 13 (2009).

GIRARD, P. F., Manuel élémentaire de droit romain, 1906.

GONZÁLEZ FERNÁNDEZ, R., Las estructuras ideológicas del Código de Justiniano, Murcia 1997.

GOMEZ ACEBO, F., Revisión del concepto de lesión; su estructura técnica, en Revista de Derecho Privado, XXXIV, 1950.

GÓMEZ CAMACHO, F. y ROBLEDO, R., El pensamiento económico en la escuela de Salamanca, Salamanca 1998.

GÓMEZ DE LA SERNA, P., Curso Histórico-Exegético del Derecho Romano comparado con el Español, I, Madrid 1869.

GONZÁLEZ FERNÁNDEZ, R., Las estructuras ideológicas del Código de Justiniano, Murcia 1997.

GRADENWITZ, Interpolazioni e interpretazioni, en BIDR, 2 (1889).

GUTIÉRREZ ALVIZ, "Laesio enormis», en Boletín de la Universidad de Granada 80, 1945.

GUZMAN BRITO, A., Derecho Privado Romano, II, Santiago - Chile, 1996.

HACKL, K., Zu den Wurzlen der Anfechtung wegen «laesio enormis», en ZSS 98 (1981).

HUVELIN, Cours élémentaire de droit romain, vol. II (1929).

JOLOWICZ, H. F., The origin of «laesio enormis» en The juridical review, March (1937).

JÖRS, P., Derecho Privado Romano, Barcelona 1965. 
KASER, M., Las interpolaciones en las fuentes jurídicas romanas, Granada 1998.

KLAMI H. T., «Laesio enormis» in Roman Law, en LABEO 33 (1987).

KUNKEL, W., Historia del Derecho Romano, Barcelona 1970.

LANDUCCI, L., La lesione enorme nella compra e vendita, en Atti del $R$. Istituto Veneto di Scienze, Lettere ed Arti, LXXV (1916).

LEICHT, P. S., "Laesio enormis e Justum pretium», en Studi di Storia e Diritto in onore di Carlo Calisse, I, Milano 1939.

MARGADANT, G. F., La historia de la»laesio enormis»como fuente de sugerencias para la legislación moderna, en Boletín Mexicano de derecho comparado 10 (1977).

MARTÍN CASALS, M., Lesió "ultra dimidium» $i$ equivalència: naturalesa de la lesió $i$ àmbit d'aplicació/tesi doctoral, Barcelona 1984.

MEYNIAL, Des conditions requises au Moyen-Age pour l'application de la rescision de la vente pour lesión d'outre-moitié, en Mélanges P. F. Girard: études de droit romain dédiées a M. P. F. Girard, Paris 1912.

MIRABELLI, G., La rescissione del contratto, Napoli 1962.

MONTAÑANA CASANÍ, A., La rescisión por lesión (origen, evolución histórica y recepción en Derecho moderno), Valencia 1999.

MUÑOZ MALDONADO, J., Elementos de la historia del Derecho Romano, Madrid 1827.

NICOLAU, M., Les origines de la «laesio enormis», en Revue Historique de Droit Français et Étranger, 15 (1936).

OBARRIO MORENO, A., La laesio enormis y su recepción, en Actas del II Congreso Iberoamericano de Derecho Romano, (1998).

ORTOLAN, M. "Historia de la Legislación Romana», Madrid 1869, 393-394.

PALAZZINI FINETTI, L., Storia della recerca delle interpolazioni nel Corpus iuris giustinianeo, Milano 1953.

PALMA, A., Humanior interpretatio. 'Humanitas' nell'interpretazione e nella normazione da Adriano ai Severi, Torino, 1992.

PARRA MARTIN, M. ${ }^{a}$ D., La rescisión del contrato en los rescriptos de Diocleciano. C.4.44. "de rescindenda venditione. La laesio ultra dimidium», en Revista General de Derecho Romano, 11 (2008).

PICIRILLO, S.v., «Rescissione», en NNDI, XV, Turín 1968.

(c) UNED. Revista de Derecho UNED, núm. 18, 2016 
PUGLIESE, G., Istituzioni di Diritto Romano, Padova 1988.

STANOJEVIC, O., "Laesio enormis» e contadini tardoromani, en Academia Romanistica Constantiniana. Atti VIII Convegno, Napoli 1990.

RASCÓN GARCÍA, C., Sobre la recepción de la "laesio ultra dimidium» como causa de rescisión de los contratos en el derecho español, en Actas del II Congreso Iberoamericano de Derecho Romano, Murcia 1998.

RICCOBONO, S., Scritti di Diritto Romano, I, Palermo 1957.

ROCA SASTRE, R. M. ${ }^{a}$, Estudios de Derecho Privado, I, Obligaciones y Contratos, Madrid 1948.

ROCA TRÍAS, M. ${ }^{a}$ E., Problemas de l'engany de mitges, en Revista Jurídica de Cataluña, 2 (1967).

SANFILIPPO, C., Istituzioni di Diritto Romano, Messina 1996.

SIRKS, B., Quelque remarques sur la possibilité d'une règle dioclétienne sur la rescission d'une vente à cause de lésion énorme (laesio enormis), en ATTI dell'Accademia romanistica constantiniana V, Perugia, 1983.

SIRKS, A. J. B., La «laesio enormis» en Droit Romain et Byzantin, en Revue d'Histoire du droit LIII (1985).

SCIUTO, P., Sulla C. D. Rescissione per Lesione Enorme, en LABEO 3 (2003).

SOLAZZI, S., L'origine storica della rescissione per lesione enorme, en BIDR, 31 (1921).

THOMASIUS, Cr., De aequitate cerebrina legis II Cod. De rescindenda venditione et eius usupractico, en Dissertationes academicae, III, 1777.

TROPLONG, De l'influence du Christianisme sur le droit civil des romains, Bruxelles 1844.

VISKY, K., Appunti sulla origine Della lesione enorme, en IVRA 12 (1961).

VOLTERRA, E., Istituzioni di Diritto Privato Romano, Roma 1961.

WESTBROOK, R., The Origin of "Laesio Enormis», en RIDA LV (2008).

ZIMMERMANN, R., The law of obligations, New York 1996. 